NASA Technical Memorandum 109114

$$
\begin{array}{r}
1 N-26 \\
13722
\end{array}
$$

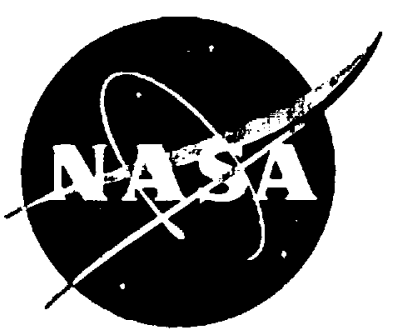

\title{
The Effects of Physical Aging at Elevated Temperatures on the Viscoelastic Creep of IM7/K3B
}

Thomas S. Gates

Langley Research Center, Hampton, Virginia

Mark Feldman

Old Dominion University, Norfolk, Virginia

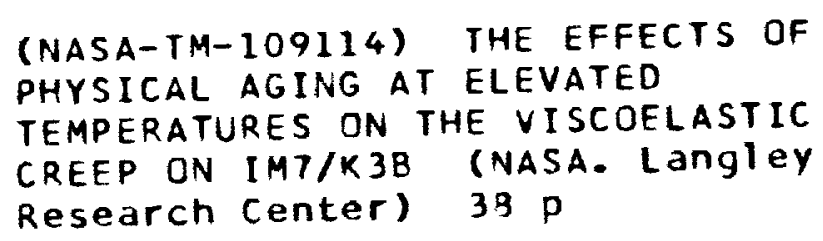

June 1994

National Aeronautics and Space Administration Langley Research Center Hampton, Virginia 23681-0001 
$-2$

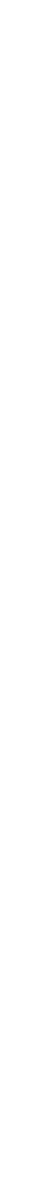




\begin{abstract}
Physical aging at elevated temperature of the advanced composite IM7/K3B was investigated through the use of creep compliance tests. Testing consisted of short term isothermal, creep/recovery with the creep segments performed at constant load. The matrix dominated transverse tensile and in-plane shear behavior were measured at temperatures ranging from 200 to $230^{\circ} \mathrm{C}$. Through the use of time based shifting procedures, the aging shift factors, shift rates and momentary master curve parameters were found at each temperature. These material parameters were used as input to a predictive methodology, which was based upon effective time theory and linear viscoelasticity combined with classical lamination theory. Long term creep compliance test data was compared to predictions to verify the method. The model was then used to predict the long term creep behavior for several general laminates.
\end{abstract}

KEY WORDS: Polymeric composites, physical aging, creep, viscoelasticity 


\section{Introduction}

Strength, stiffness and weight considerations make polymer matrix composites (PMC's) desirable for structural materials in such diverse applications as aircraft, civil infrastructure and biomedical implants. One common aspect shared by structural designers and material developers for all these PMC applications is the concern for long term durability. When considering durability, adverse environmental conditions, high loads, elevated temperature and fatigue may all play a role in determining the useful lifetime of a PMC structure. To address these problems, accurate analytical predictive methods and comprehensive material property characterization techniques are essential.

One material behavior which is ubiquitous to all polymeric materials is physical aging. This type of aging is a thermoreversible process which occurs due to the evolution of the free volume in a polymer toward thermodynamic equilibrium after cooling below the glass transition temperature $\left(\mathrm{T}_{\mathrm{g}}\right)$. This evolutionary process may be affected by many parameters including temperature, moisture and stress. Struik(1) showed that it was possible to isolate the physical aging process in polymers from other behaviors by performing isothermal creep compliance tests and using superposition techniques to establish the aging related material constants. Linear viscoelasticity was used to characterize the creep and the "effective time" theory was developed to aid in predicting the long term creep compliance from short term test data.

It is the intent of this paper to utilize the test techniques and analysis tools given by Struik(1), and adapt them to the elevated temperature characterization of physical aging in an advanced graphite/thermoplastic PMC. For the purposes of this research, short term was defined as tests spanning approximately 3 decades of time whereas long term was defined as tests spanning approximately 5 decades. Material property testing consisted of short term, isothermal, creep/recovery with the creep segments performed at constant load. Both transverse tensile and in-plane shear behavior were measured. Through the use of time based shifting procedures, the aging shift factors, shift rates and momentary master curve parameters were found at each temperature.

These material parameters were used as input to a predictive methodology given by Brinson and Gates(2) which was based upon effective time theory and linear viscoelasticity combined with classical lamination theory. Long term creep compliance test data were compared to predictions to verify the method. 
The model was then used to predict the long term behavior for several general laminates.

Traditionally, time/temperature superposition (TTSP) provides a method by which long term behavior can be predicted from short term tests, thereby providing an accelerated test scheme. As described by Griffith et.al(3), TTSP has a long history of use in viscoelastic characterization of materials and a number of procedures have been proposed to arrive at the TTSP master curve. However, for long term creep, Struik's(1) work with polymers and more recently tests on PMC's by Sullivan et.al(4) have shown that TTSP by itself is not sufficient to account for the long term effects of physical aging. This has led to the development of the effective time theory as a way of predicting the effects of physical aging.

\section{Material System}

The PMC material used in this study was a continuous carbon fiber reinforced, amorphous thermoplastic polyimide. The material was fabricated by DuPont and designated IM7/K3B. The as received $\mathrm{T}_{\mathrm{g}}$ was $240^{\circ} \mathrm{C}$ as measured by Dynamic Mechanical Analyzer (DMA) G" peak. Chemical aging of the K3B polymer was not expected to occur. For this study, it was therefore assumed that the $\mathrm{T}_{\mathrm{g}}$ of IM7/K3B would remain constant over the duration of the material characterization tests used in the current study.

All methods verification and material property tests utilized a rectangular specimen of approximately $241 \mathrm{~mm} \times 25 \mathrm{~mm}$ with a 12 or 8 ply thickness. Per ply thickness was approximately $.0135 \mathrm{~cm}$. The transverse and shear creep compliance data came from $[90]_{12}$ and $[ \pm 45]_{2}$ s specimen layups respectively. Three to four replicates were used at each test temperature. Although all the specimens came from the same material lot, many of the replicate specimens were cut from different panels.

\section{Test Procedures}

Testing was performed to understand material behavior, develop material constants for the analytical model and to provide verification of the predictive model. This section will highlight some of the important test procedures. Specific procedures and techniques relating to testing may also be found in Feldman and Gates(3).

\section{Short Term Testing}

The test temperatures selected for the study were $200^{\circ}, 208^{\circ}, 215^{\circ}, 225^{\circ}$, and $230^{\circ} \mathrm{C}$. These temperatures were selected to ensure that measurable aging 
occurred within the test period. Prior to testing, the specimen was heated to $250^{\circ} \mathrm{C}\left(10^{\circ}\right.$ above $\left.\mathrm{T}_{\mathrm{g}}\right)$ for 20 minutes. By rapidly quenching the specimen from above $\mathrm{T}_{\mathbf{g}}$ to the test temperature, it was ensured that all test specimens started the test sequence in the same unaged condition. This procedure was based upon work by Struik(1) and others who showed physical aging is thermoreversible and the excursion above $\mathrm{T}_{\mathrm{g}}$ prior to quenching effectively rejuvenates the material.

A well documented(1) technique to explore physical aging is a series of sequenced creep (constant load) and recovery tests as shown in figure 1 . The basic procedure is that while the specimen isothermally ages, periodic creep tests are performed using a constant applied load. For this study, the duration of each creep test was $1 / 10$ th the duration of the prior total aging time. These creep tests are termed momentary tests. The aging times (time after quench) selected for starting each creep segment were $2,4,10,24,48,72$ and 96 hours. Figure 2 shows creep compliance data from a typical sequenced test. The curves in figure 2 have a similar shape on the double log plot and are shifted horizontally relative to the initial ( 2 hour) curve. This shift is an indication that physical aging affects creep compliance. The effects of sequencing on the test results were examined by Gates and Feldman(4) where it was determined that the sequencing procedure had little or no effect on the data.

All creep tests were performed in convection ovens. Thermocouples monitoring the test temperature and providing feedback for the oven controller were placed near the test section. Load was applied through a dead-weight cantilever arm arrangement. Strain in the gage section was measured with high temperature foil strain gages applied back to back at the center of the specimen.

Between the creep segments of the sequenced test, creep recovery took place. To facilitate recovery, the specimen remained in the oven at temperature while being completely unloaded. Strain data were taken during both the creep and recovery segments. Residual strain due to lack of complete recovery was accounted for by fitting the final part of the recovery curve with a linear function and subtracting the extrapolated recovery strain from the subsequent creep strain. Figure 1 illustrates this extrapolated recovery strain. Strain variations during the course of the test due to thermal apparent strain were accounted for through the use of the thermal apparent strain correction technique(5).

\section{Linearity}

The stress levels for the creep tests were chosen based on linearity checks at the highest test temperature for a given layup. For linear viscoelastic behavior, it was assumed that superposition and proportionality conditions would be 
met. Given an initial state of stress $\sigma^{\prime}$ applied for a time $t$ and an additional stress $\sigma^{\prime \prime}$ applied at a time $t_{1}$, Boltzman's superposition principle(6) states that:

$$
\varepsilon\left[\sigma^{\prime}(t)+\sigma^{\prime \prime}\left(t-t_{1}\right)\right]=\varepsilon\left[\sigma^{\prime}(t)\right]+\varepsilon\left[\sigma^{\prime \prime}\left(t-t_{1}\right)\right]
$$

Therefore, equation 1 implies that given creep data, superposition would allow the exact prediction of the subsequent recovery period so that

$$
\varepsilon\left(t^{*}\right)=\sigma\left\{S(t)-S\left(t-t_{1}\right)\right\}
$$

where $\sigma$ is the constant stress, $t_{1}$ is the time of load removal, $t^{*}$ is the time during strain recovery and $S(t)$ is the creep compliance function. Creep and creep/recovery data provided data for checking superposition.

Proportionality states that for an applied stress $\sigma$, the strain in a material at any other stress state is found using:

$$
\varepsilon[c \sigma(t)]=c \varepsilon[\sigma(t)] \text { where } c=\text { constant }
$$

Proportionality was checked by plotting isothermal, creep compliance versus test time for a specimen that was repeatedly rejuvenated, quenched and loaded at various stress levels. The supposed transition from linear to nonlinear behavior would be evident by the vertical separation of the compliance curves with increasing stress. These checks for proportionality were made at the lowest and highest test temperatures thereby ensuring that the effects of applied stress were minimized for all temperatures and a linear assumption could be used in the model with assurance of reasonable accuracy.

\section{Long Term Testing}

For a time scale measured in $\log$ seconds, the short term test data required by the analytical model spanned approximately 2.5 to 3 decades. To verify the analytical predictions of long term creep compliance, long term tests were run with data taken over approximately 5 decades of time. Test procedures prior to initial loading were the same as those used in the short term tests. The initial unloaded aging time was 2 hours. After load application, the specimen remained loaded at a constant load for the entire duration of the test period. Therefore, aging proceeded for approximately the same time as the total loaded test time. It was expected that the effects of aging on the creep compliance would become apparent after the total aging time exceed the time span used in the momentary tests. 


\section{Analytical Model}

An analytical model was developed(2) to predict the long term creep compliance given the short term data as input. Defining "long term" as any time greater than the time scale of the material property tests, it was expected that the model would provide insights into the effects of physical aging on the long term viscoelastic behavior of advanced polymeric composites.

\section{Linear Viscoelastic Creep Compliance}

The ability to satisfy Boltzman superposition and proportionality requirements were the conditions necessary for linear viscoelastic behavior. In general, the time dependent linear creep compliance was modeled with a three parameter expression given by

$$
S(t)=S^{o} e^{(t / \tau)^{\beta}}
$$

where $S^{\circ}, \tau$, and $\beta$ are the initial compliance, retardation time and shape parameter respectively.

\section{Time Based Superposition}

Time/aging-time superposition of the short term creep compliance test data provided the means for the data to be collapsed into a single momentary master curve (MMC) at each test temperature. As demonstrated by Struik(1) and illustrated in figure 2, horizontal separation of the sequenced creep compliance curves is due to aging and can be characterized by the aging shift factor $(-\log$ a). This shift factor is simply defined as the horizontal distance required to shift a compliance curve to coincide with a reference compliance curve. A linear fit of all the shift factors versus the logarithmic aging time (log $\left.t_{e}\right)$ for each $M M C$, gave the aging shift rate

$$
\mu=-\frac{d \log a}{d \log t_{e}}
$$

The reference compliance curve could be any of the sequenced curves, but for convenience of data manipulation, the longest ( 96 hour) compliance curve was selected as the reference during formation of the MMC. However, to facilitate data reporting, all MMC parameters were referenced to the shortest (2 hour) compliance curve. For a horizontal (time) translation of a compliance curve, only the retardation time parameter needs to be recalculated. Given the aging shift rate and reference curve parameters, the translation from one aging time to another was accomplished through the use of 


$$
\tau\left(t_{e}\right)=\tau_{\text {ref }}\left(\frac{t_{e}}{t_{\text {eref }}}\right)^{\mu}
$$

where $t_{\text {eref }}$ is the reference aging time as given in Brinson and Gates(2).

Equation 5 implies a linear relation between $\log a$ and $\log t_{e}$. Figure 3 shows this relationship for one of the replicate tests used to establish the MMC's. The shift factors for the data on figure 3 were found from the curves on figure 2 and are representative of all the IM7/K3B MMC data.

To facilitate the collapse of the shifted data for the MMC, vertical (compliance) shifts were also utilized. These shifts were small in comparison to the magnitude of the horizontal (time) shifts. This use of small vertical shifts in reduction of PMC creep compliance/aging data was also reported by Sullivan et.al(7) and Hastie et.al(8). A recent report by the authors(3) determined that combined horizontal and vertical shifts had little effect on the resulting shift rates when compared to the shift rate found through horizontal shifting only.

\section{Composite Physical Aging}

To provide the analytical model necessary to make long term creep compliance predictions for PMC's, Brinson and Gates (2) developed a time dependent form of laminated plate theory which incorporated Struik's(1) effective time theory. For a single lamina under plane stress conditions, the stress-strain relations for any fiber orientation are given in Jones(9) by

$$
\left\{\begin{array}{l}
\varepsilon_{x x} \\
\varepsilon_{y y} \\
\gamma_{x y}
\end{array}\right\}=[\bar{S}]\left\{\begin{array}{l}
\sigma_{x x} \\
\sigma_{y y} \\
\tau_{x y}
\end{array}\right\}
$$

where $\varepsilon_{\mathrm{ij}}$ and $\sigma_{\mathrm{ij}}$ represent the strain and stress in the body axis directions and $[\bar{S}]$ is the transformed compliance matrix given by

$$
[S]=\left[T \Gamma^{-1}[S \mathbf{I} T]\right.
$$

where $[\mathrm{T}]$ is the transformation matrix and $[\mathrm{S}]$ is the compliance matrix referenced to the material coordinate axis given by

$$
[S]=\left[\begin{array}{ccc}
S_{11} & S_{12} & 0 \\
S_{12} & S_{22} & 0 \\
0 & 0 & S_{66}
\end{array}\right\rfloor
$$


As demonstrated by Sullivan et.al(6) and Hastie et.al (7), the only time dependent compliance terms in equation 9 are the transverse $\left(S_{22}\right)$ and shear $\left(S_{66}\right)$. Therefore, using equation 4 , the two time dependent terms are given as

$$
\begin{aligned}
& S_{22}(t)=f\left(S_{22}^{0}, \beta_{22}, \tau_{22}\left(t_{\text {eref }}\right), \mu_{22} ; t\right) \\
& S_{66}(t)=f\left(S_{66}^{0}, \beta_{66}, \tau_{66}\left(t_{\text {eref }}\right), \mu_{66} ; t\right)
\end{aligned}
$$

where $t_{e r e f}$ is the reference aging time.

For the laminated composite plate, the laminate compliance referenced to the body axis are $S_{x}, S_{y}$, and $S_{x y}$ which are found by using the lamina compliance terms given above and the normal laminated plate theory as given by Jones(9). Due to the time dependence of equations 10 and 11 , the laminate compliance will also be time dependent. The amount of time dependence and the effects of aging will depend on the layup and therefore the relative contributions of equations 10 and 11 to the total laminate compliance.

\section{Long Term Compliance}

For test periods which exceed the time required to collect the short term (momentary) data, the response can be expected to be influenced by the ongoing aging process. Struik(1) proposed an effective time which could be used to replace the time such that the compliance in equation 4 would be written as

$$
S(t)=S^{o} e^{\left(\lambda / \tau\left(t_{0}^{0}\right)\right)^{\rho}}
$$

where $\lambda$ is the effective time and is calculated according to

$$
\begin{aligned}
& \lambda=t_{e}^{0} \ln \left(\frac{1}{t_{e}^{0}}+1\right) \text { for } \mu=1 \\
& \lambda=\frac{t_{e}^{0}}{1-\mu}\left[\left(1+\frac{t}{t_{e}^{0}}\right)^{1-\mu}-1\right] \text { for } \mu \neq 1
\end{aligned}
$$

where $t_{e}^{o}$ is the aging time prior to loading and at some time later during the test the aging time is $t+t_{e}^{o}$ where $t$ is the test time. Use of the effective time expressions in the laminated plate model allowed for the prediction of long term creep compliance. Input to the model was the material parameters measured from short term tests. 


\section{Results}

\section{Linearity}

Coincidence of the compliance curves in figures 4 and 5 indicated that stress caused less than $15 \%$ variation in compliance on the log scale. In addition, figures 4 and 5 show no clear trend in location of the curves in relation to the applied stress. Based upon these results and the fact that the same applied stress level was used at all temperatures, it was assumed that proportionality was met for all tests. From data such as that shown in figure 6 , it was also assumed that the linear superposition condition was met for all tests. It was recognized that the assumption of linear viscoelastic behavior based upon these results might not be conclusive, however it was felt that deviations from linearity were small enough to confidently proceed with the linear model. The final applied stress levels chosen for the creep tests were $2.66 \mathrm{MPa}$ and 6.81 $\mathrm{MPa}$ for the transverse and shear tests respectively.

\section{Momentary Compliance Master Curves}

As mentioned, three to four replicate specimens were used to generate the isothermal momentary master curves (MMC's) for $S_{22}$ and $S_{66}$. The MMC parameters $\left(S^{0}, \tau, \beta\right)$, given in table 1 , were found by fitting equation 1 to the combined data sets from all replicates. Figures 7-15 show the resultant MMC's with selected error bars included to indicate the spread in the data. The magnitude of these errors were less than $.18 \mathrm{GPa}$ with most measured errors significantly smaller than this. In general, the $S_{66}$ (shear) compliance data was better behaved than the $S_{22}$ (transverse) data.

It should be noted that even though only one set of MMC parameters are given in table 1 , each of the replicate tests had their own shift rate $(\mu)$ found through the procedures described previously. Therefore, the shift rate given in table 1 is an average value. The number of replicate tests and the standard deviation of $\mu$ are also provided in table 1 . The average shift rates are plotted versus test temperature in figures 16 and 17 for the shear and transverse compliance respectively. The data points in these figures were connected with a smooth curve to illustrate the trends.

For comparison purposes, the resultant MMC's for each temperature are plotted together in figures 18 and 19 for the transverse and shear compliance respectively. The error bars of the previous figures were not included for clarity. These curves represent the sum of all the short term sequenced creep compliance data. 


\section{Time-Temperature Superposition Master Curves}

The isothermal MMC's for each compliance direction could also be collapsed by using time/temperature superposition (TTSP). Each set of isothermal MMC's (figures 18 and 19) was collapsed to coincide with the $200^{\circ} \mathrm{C}$ curve to form the TTSP master curves shown in figures 20 and 21 . The TTSP shift rates were found from a linear fit to time shift factor $\left(\log \bar{a}_{T}\right)$ versus temperature. The shift rates associated with each TTSP master curve were .059 and $.049\left(\log (\mathrm{sec}.) /{ }^{\circ} \mathrm{C}\right)$ for the transverse and shear compliance respectively. TTSP shift rates along with the aging time shift rates $(\mu)$ can be used in expressions such as those given in Brinson and Gates (2) to aid in data reduction and interpretation.

\section{Methods Verification}

Data from several long term (approximately 1200 hours) creep tests were used to verify the predictive methodology. These data were compared to the long term predictions made using the short term MMC data of table 1 and the analytical methods outlined above. Figures 22-24 show data and predictions for transverse and shear creep compliance at 215 and $225^{\circ} \mathrm{C}$. Figure 23 includes predictions at $225^{\circ}, 227^{\circ}$ and $230^{\circ} \mathrm{C}$ to illustrate the temperature sensitivity of long term creep when testing close to $\mathrm{T}_{\mathrm{g}}$. The momentary curves in these figures were predicted from the short term data without accounting for aging effects. The long term predictions relied upon the effective time theory to handle the aging effects. To test beyond 7 decades would require over 3 months and to test beyond 8 decades would require over 3 years. The facilities for such long term tests were not available in this study.

\section{Long Term Predictions}

The parameters in table 1 and the analytical model were used to predict the effects of aging on the isothermal, constant load compliance of quasi-isotropic and $[ \pm 45 / 90]_{s}$ laminated IM7/K3B plates. The compliance values in the predictions were normalized to the initial value to show the relative changes. Predictions were made out to 8 decades of time which is approximately 3.2 years.

Figure 25 shows predictions of $S_{y}$ and $S_{x y}$ for a quasi-isotropic laminate at $225^{\circ} \mathrm{C}$. This figure illustrates the differences in the individual compliance terms as well as the aging time dependent behavior of a fiber dominated laminate.

To demonstrate the predicted dependence on test temperature, figure 26 shows the long term behavior of $S_{y}$ at 200,215 and $225^{\circ} \mathrm{C}$. Figure 27 shows the dependence of long term creep compliance on laminate layup. In this figure, $S_{y}$ was predicted for a quasi-isotropic and a $[ \pm 45 / 90]_{s}$ laminate at 
$215^{\circ} \mathrm{C}$. The differences between a fiber versus matrix dominated layup are clearly evident.

\section{Summary and Discussion}

\section{Error Analysis}

Replicate tests on specimens cut from different panels revealed specimen to specimen scatter in the data. This is clearly demonstrated by the error bars of figures 7-15. However, as shown by Feldman and Gates(3), repeat tests on the same specimen generated only small deviations (less than $5 \%$ ) in the results. These results coupled with the strict adherence to test procedures and periodic calibration of all test equipment leads to the belief that experimental errors inherent in the data were minimized. The primary source of error in the data was felt to be the panel-to-panel material inconsistencies. One additional factor to note however, is that the material property tests and the long term verification tests were run on different test stands. Consequently, slight differences in specimen thermal profiles and temperature stability should be considered a source of data error.

\section{Material Master Curves}

The material momentary master curves of figures 18 and 19 show the clear temperature dependency of short term creep compliance. The ordering of the curves was as expected with the highest temperatures resulting in the highest creep compliance. The directional dependency of the PMC is also evident by noting the differences in the compliance between the transverse and shear tests.

Aging time shift rates found from the isothermal MMC's showed a clear temperature dependency over the range investigated. As shown in figures 16 and 17 , as test temperature approached $T_{g}$, the shift rate $(\mu)$ decreased. Additional data over a wider range of temperatures would be required to establish global maximums and minimums. At $\mathrm{T}_{g}$, the polymer is in equilibrium and theoretically, a shift rate of zero would indicate a material exhibiting no aging behavior. Although the shift rate was assumed constant over time at a given temperature, results by Lee and McKenna(10) indicated that a polymer may exhibit a change in shift rate as it ages into a equilibrium state. However, to reach this condition would require a long aging time and/or aging temperatures very close to $\mathrm{T}_{\mathrm{g}}$. Modeling of this time dependent change in shift rate and the implications in regards to the effective time theory were explored in Brinson and Gates(2).

Collapsing the MMC's to form the TTSP master curves was performed using horizontal shifts only. For the ideal case, these curves should collapse 
completely. The scatter evident in figures 20 and 21 are due to the sources of scatter in the MMC's as explained above. Despite this scatter, the results demonstrates that TTSP will work satisfactorily on short term data.

\section{Predictive Model}

The predictive model provided a means of analytically studying the effects of physical aging on long term creep compliance. Figures 22-24 indicate that the model does a good job of predicting the long term creep compliance from short term data. All of these figures show the long term prediction to be lower than the test data. Part of the differences between test and prediction may be due to the material inconsistencies mentioned previously. Figure 23 illustrates that the differences between test and prediction may also be due to slight variations in test temperature. Comparing the momentary versus long term predictions in figures 22-24 illustrates the large errors which would occur if predictions did not include the effects of aging.

For the cases investigated to date, the coupling of linear viscoelasticity, classical lamination theory and effective time theory has provided a good predictive model for long term creep. Barring the occurrence of creep rupture or aging into equilibrium, it was not expected that creep compliance data greater than 7 decades of time would deviate significantly from the trends indicted in the data of figures 22-24. However, without actual data, the complete verification of a prediction spanning years is not feasible.

Comparison of the analytical model to 1200 hour test data provided the confidence to use the model for parametric studies such as shown in figures 25-27 for laminates under constant load and temperature. As indicated by these figures, even a fiber dominated laminate may exhibit sensitivity of certain material parameters to aging time and temperature. 


\section{References}

[1] Struik, L.C.E., Physical Aging in Amorphous Polymers and Other Materials, Elsevier Scientific Publishing Company, New York, 1978.

[2] Brinson, L. C. and Gates, T. S., "Effects of Physical Aging on Long-Term Creep of Polymers and Polymer Matrix Composites.",NASA Langley Research Center TM109081, February, 1994.

[3] Griffith, W. I., Morris, D. H., and Brinson, H. F., "The Accelerated Characterization of Viscoelastic Composite Materials," Virginia Tech Center for Adhesion Science, VPI-E-80-15, Virginia Polytechnic Institute and State University, April, 1980.

[4] Sullivan, J. L., Blais, E. J. and Houston, D., "Physical Aging in the Creep Behavior of Thermosetting and Thermoplastic Composites," Composites Science. and Technology, Vol. 47, 1993.

[5] Feldman, M. and Gates, T. S., "Physical Aging Above $200^{\circ} \mathrm{C}$," SEM Spring Conference, Society for Experimental Mechanics, Baltimore, Maryland, May, 1994.

[6] Gates, T. S. and Feldman, M., "The Effects of Stress and Physical Aging on the Creep Compliance of a Polymeric Composite," NASA Langley Research Center TM109047, November, 1993.

[7] Murry, W.M., and Miller, W.R., The Bonded Electrical Resistance Strain Gage, Oxford University Press, New York, 1992.

[8] Ferry, J. D., Viscoelastic Properties of Polymers, 3rd Edition. John Wiley and Sons, Inc., New York. 3rd Edition, 1980.

[9] Hastie, R. L. and Morris, D. H., "The Effect of Physical Aging on the Creep Response of a Thermoplastic Composite.", ASTM STP \# 1174, High Temperature and Environmental Effects in Polymer Matrix Composites, Editors, C. Harris and T. Gates, 1992.

[10] Jones, R. M., Mechanics of Composite Materials. Scripta Book Company, Washington, D.C. 1975.

[11] Lee, A. and McKenna, G.B., "The Physical Ageing Response of an Epoxy Glass Subjected to Large Stresses," Polymer, Vol. 31, March, 1990. 


\begin{tabular}{|c|c|c|r|c|c|c|c|}
\hline $\begin{array}{c}\text { Compl. } \\
\text { Term }\end{array}$ & Temp. $\left(^{\circ} \mathrm{C}\right)$ & $\begin{array}{c}\mathrm{S}^{0} \\
(1 / \mathrm{GPa})\end{array}$ & $\tau$ (sec.) & $\beta$ & $\mu$ & $\begin{array}{c}\Delta \mu \\
(\text { std. dev. })\end{array}$ & $\begin{array}{c}\text { number of } \\
\text { replicates }\end{array}$ \\
\hline \multirow{5}{*}{$S_{22}$} & 200 & .133 & 156347. & .423 & .864 & .139 & 3 \\
& 208 & .130 & 123003. & .366 & .927 & .016 & 3 \\
& 215 & .127 & 76897. & .315 & .999 & .030 & 3 \\
& 225 & .134 & 17588. & .297 & .876 & .092 & 3 \\
& 230 & .118 & 2829. & .231 & .482 & .068 & 4 \\
\hline \multirow{3}{*}{$S_{66}$} & 200 & .238 & 55550. & .383 & 1.051 & .030 & 3 \\
& 208 & .236 & 28874. & .362 & 1.070 & .030 & 3 \\
& 215 & .239 & 9186. & .382 & 1.017 & .056 & 4 \\
& 225 & .227 & 2404. & .301 & .928 & .082 & 4 \\
\hline
\end{tabular}

Table 1. Momentary master curve parameters for both the transverse and shear creep compliance. 


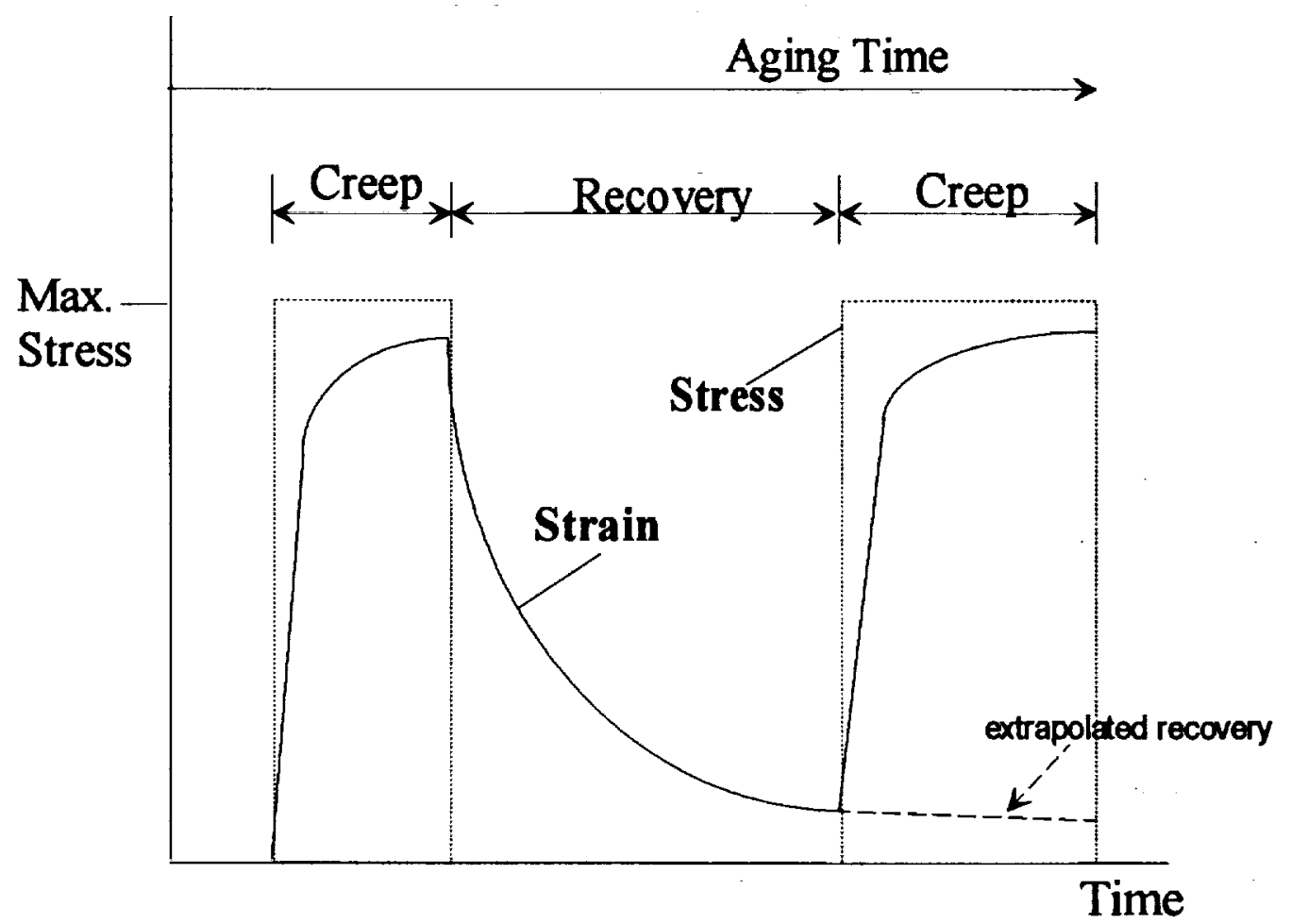

Figure 1: Schematic illustrating sequenced creep/recovery tests. 


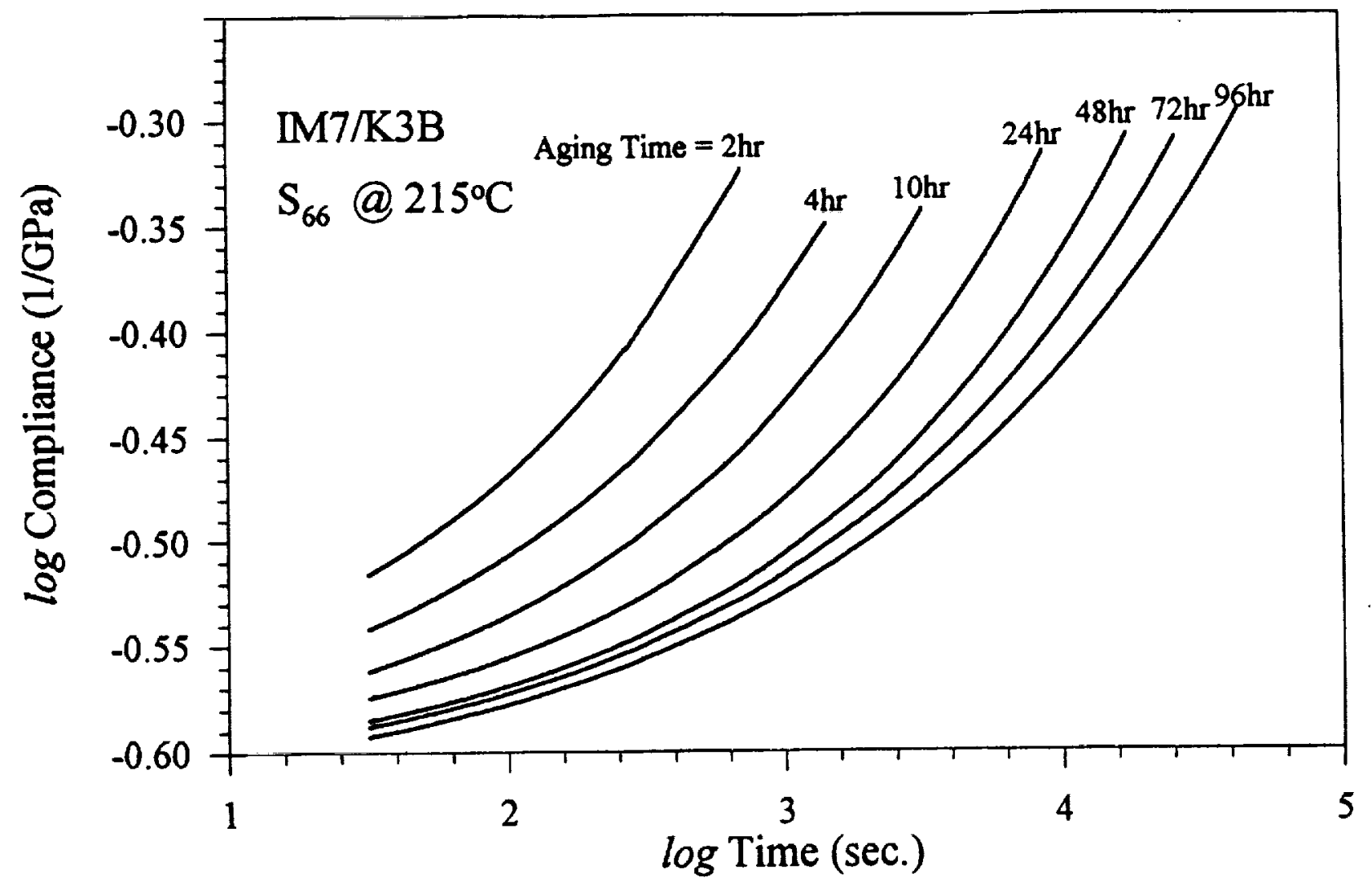

Figure 2: Typical shear compliance momentary curves.

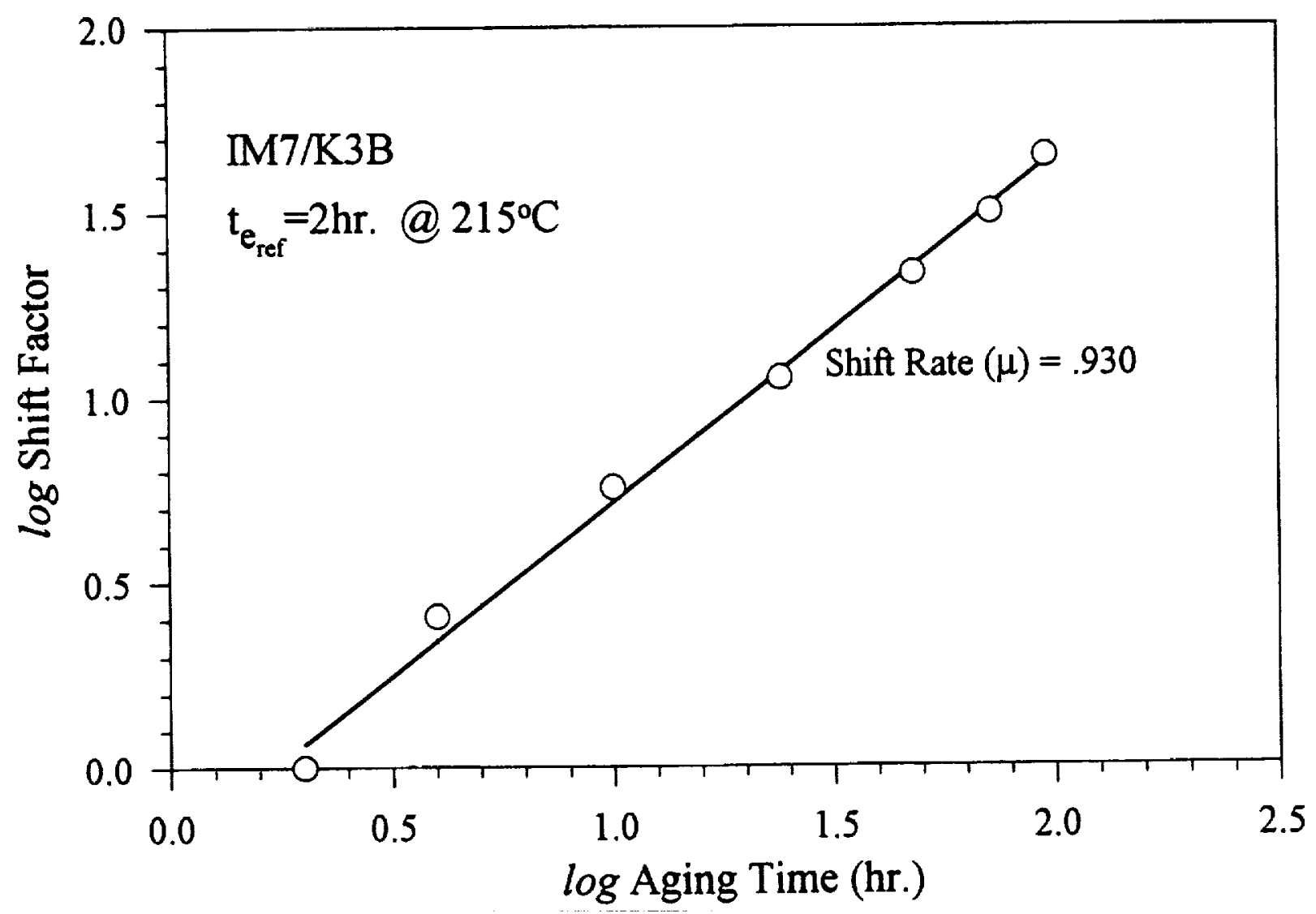

Figure 3: Typical aging shift factor as a function of aging time. 


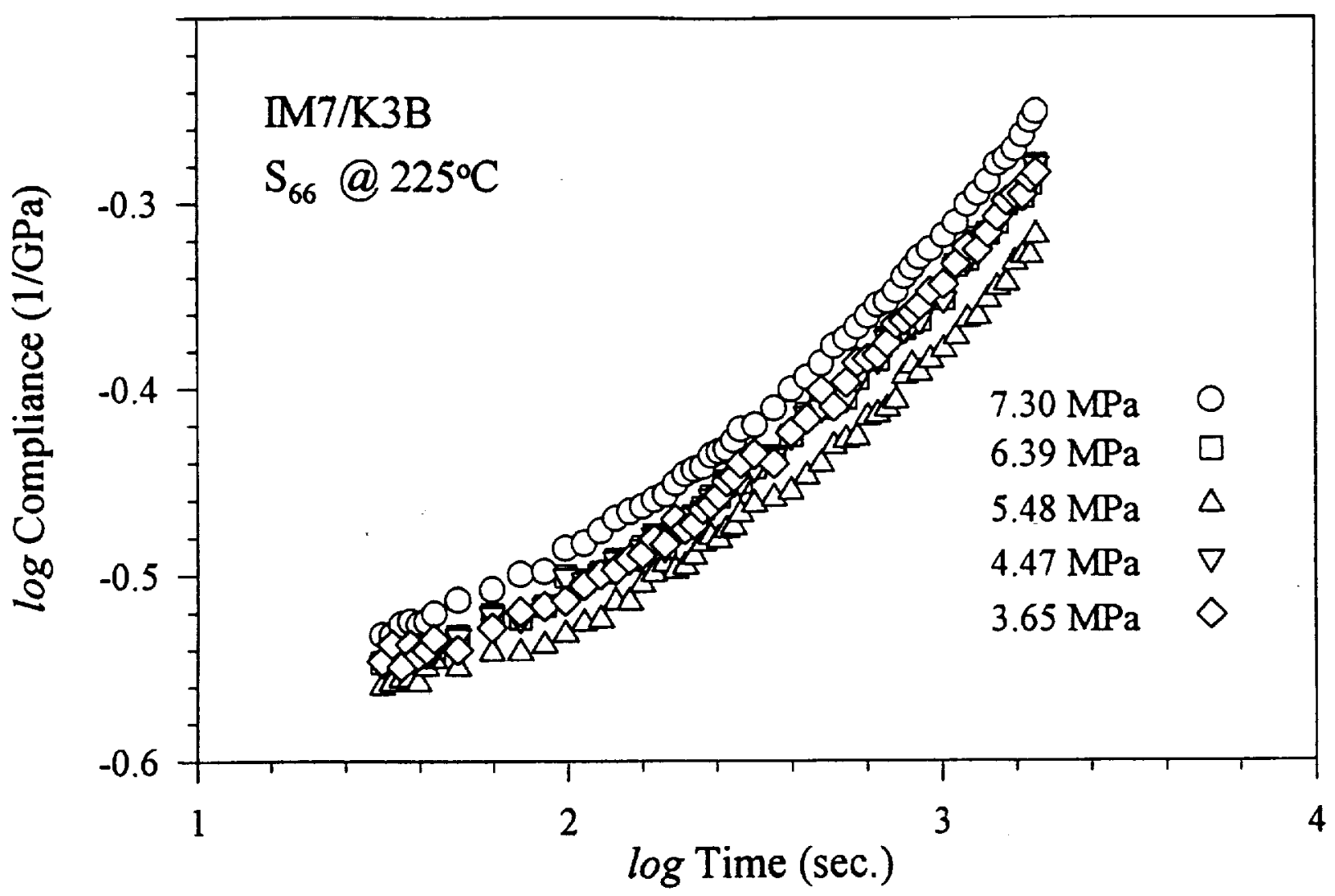

Figure 4: Shear compliance proportionality check.

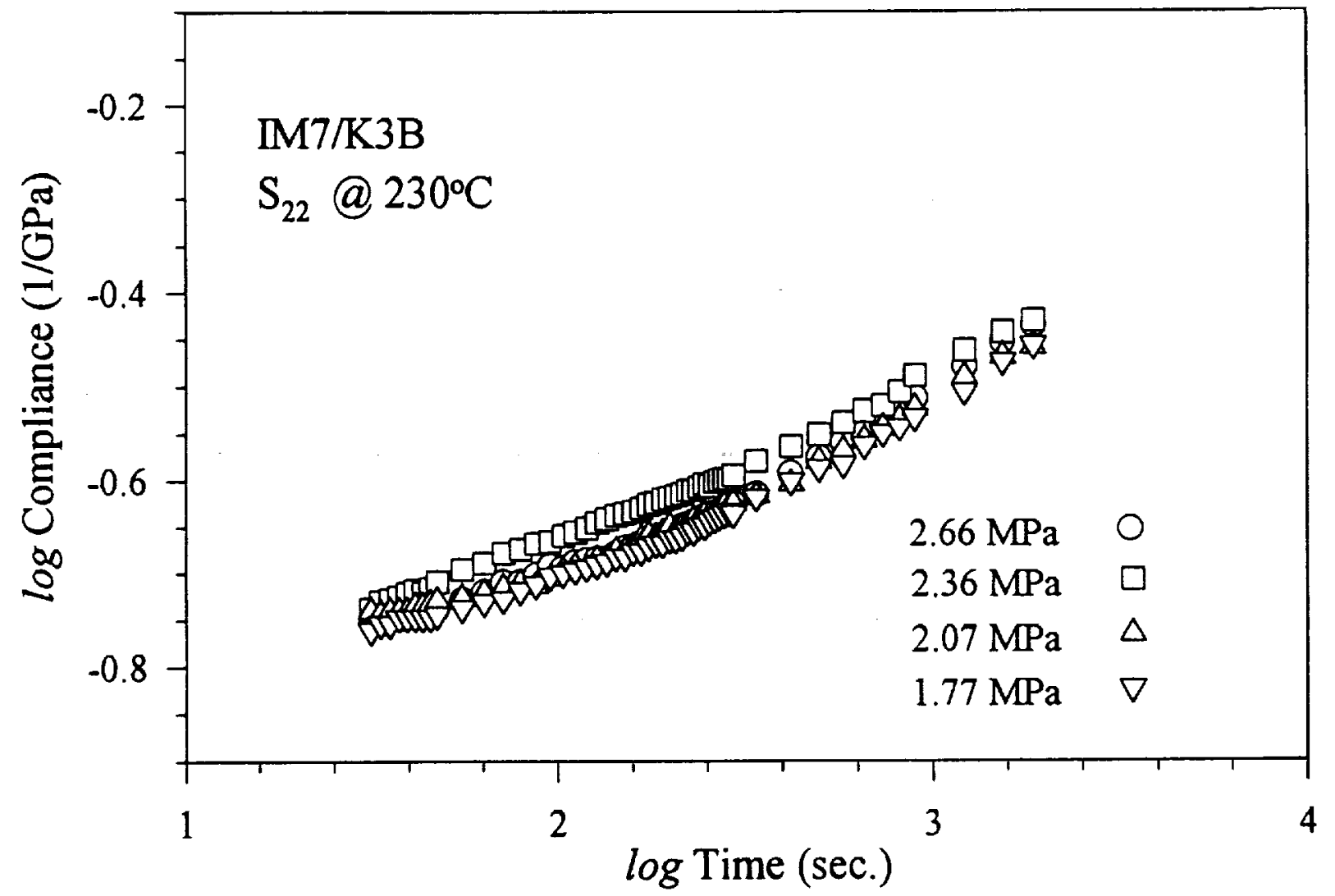

Figure 5: Transverse compliance proportionality check. 


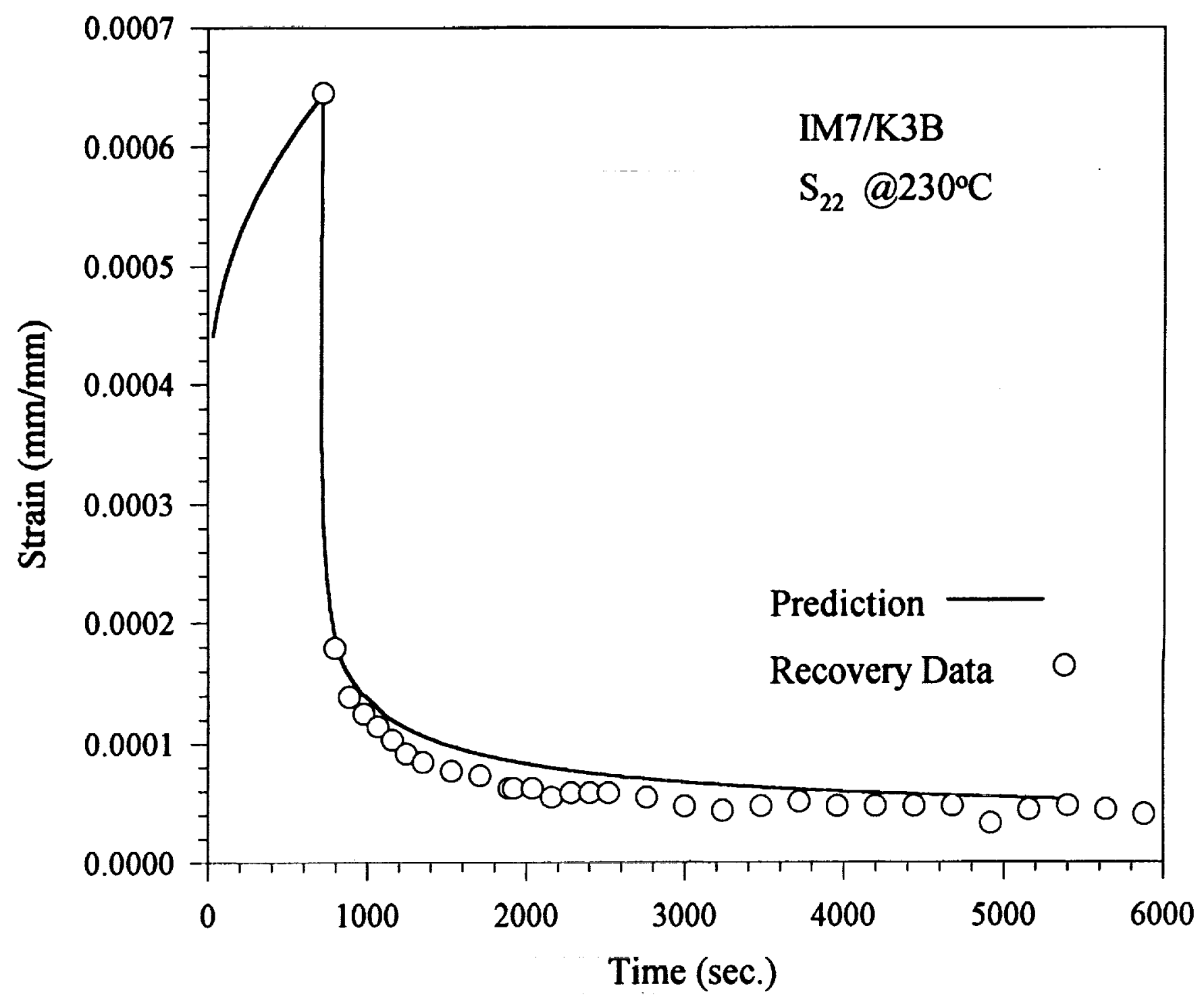

Figure 6: Linear superposition creep / recovery sequence. 


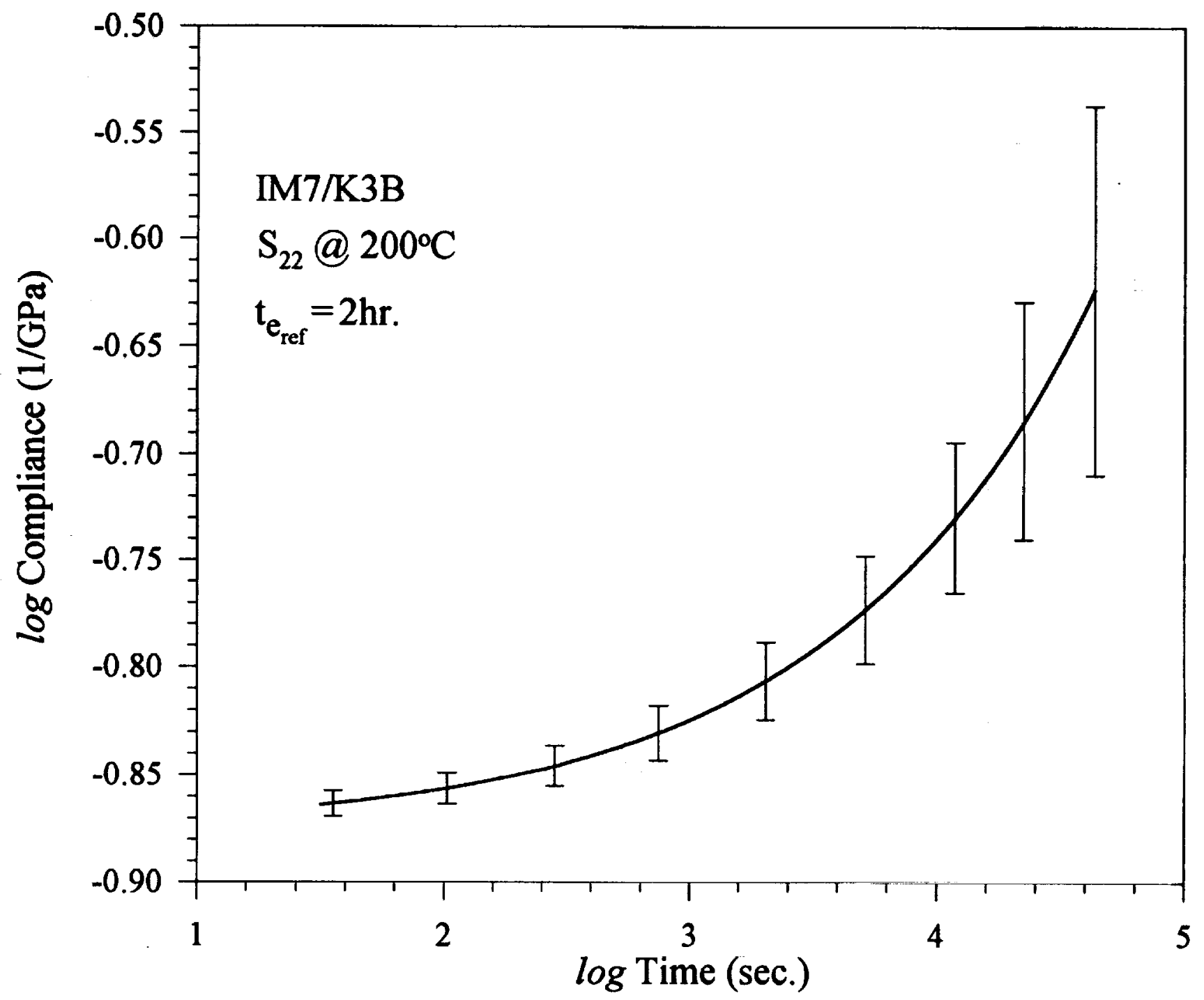

Figure 7: Transverse compliance $\mathrm{MMC}$ at $200^{\circ} \mathrm{C}$. 


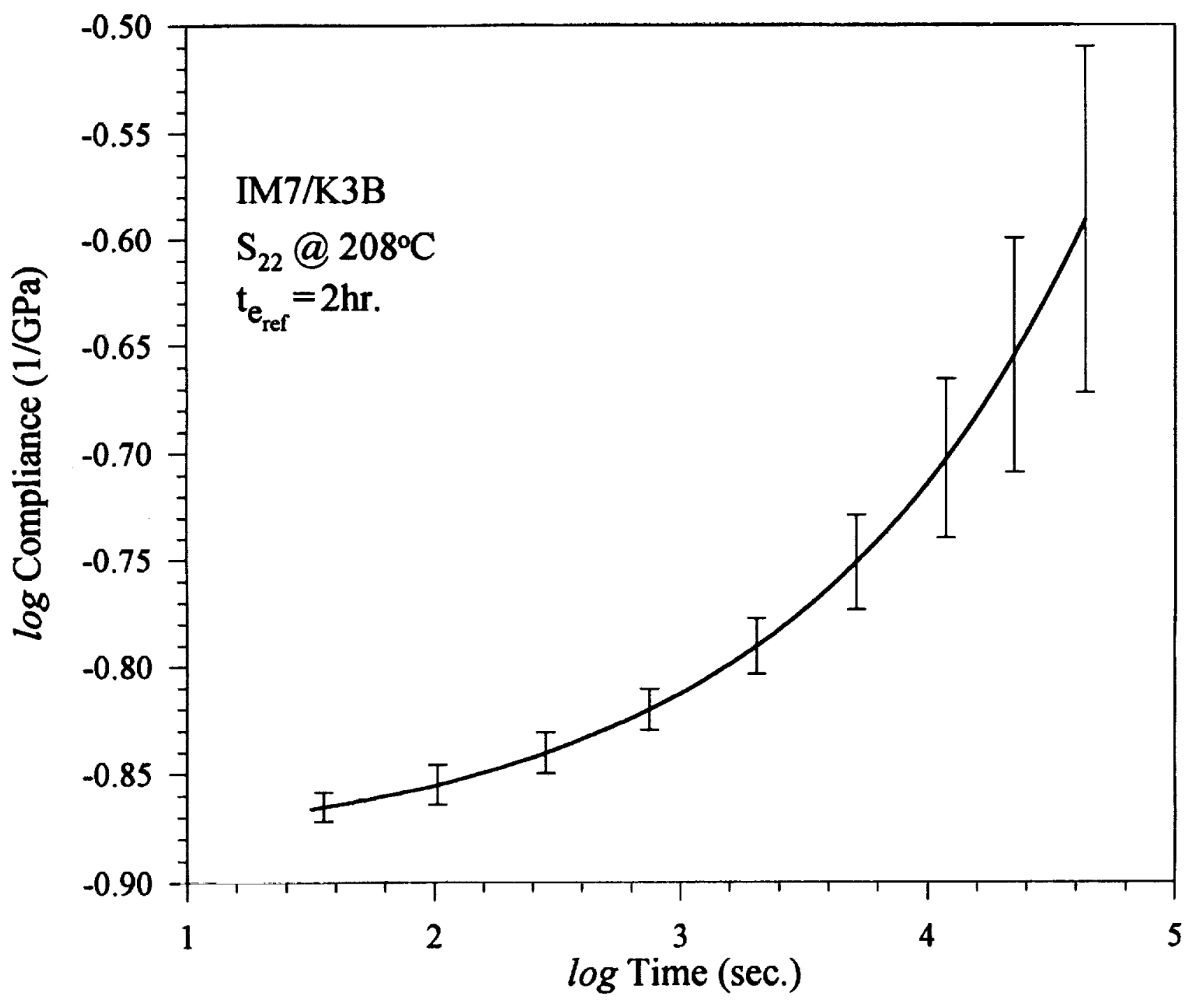

Figure 8: Transverse compliance $\mathrm{MMC}$ at $208^{\circ} \mathrm{C}$. 


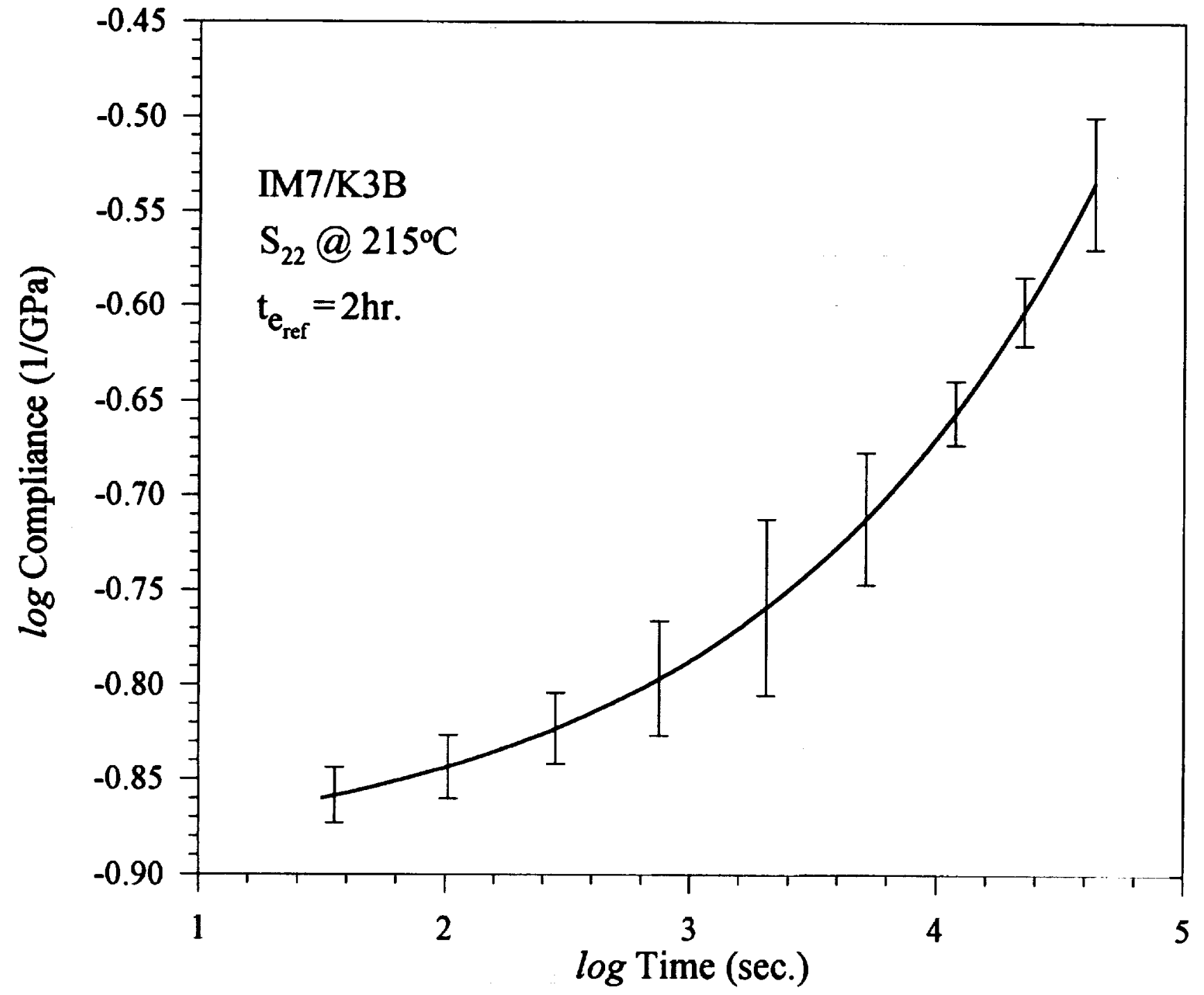

Figure 9: Transverse compliance $\mathrm{MMC}$ at $215^{\circ} \mathrm{C}$. 


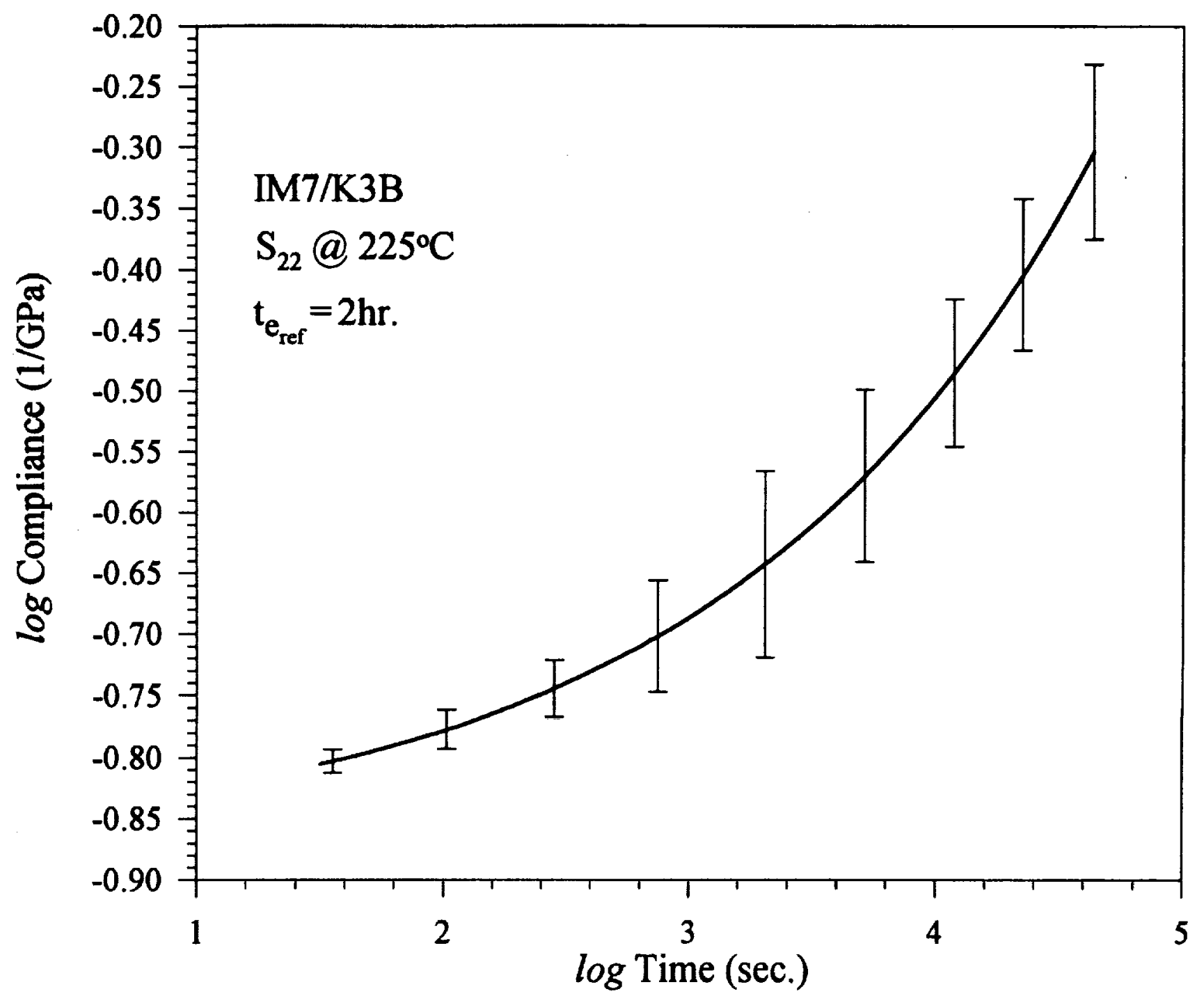

Figure 10: Transverse compliance $\mathrm{MMC}$ at $225^{\circ} \mathrm{C}$. 


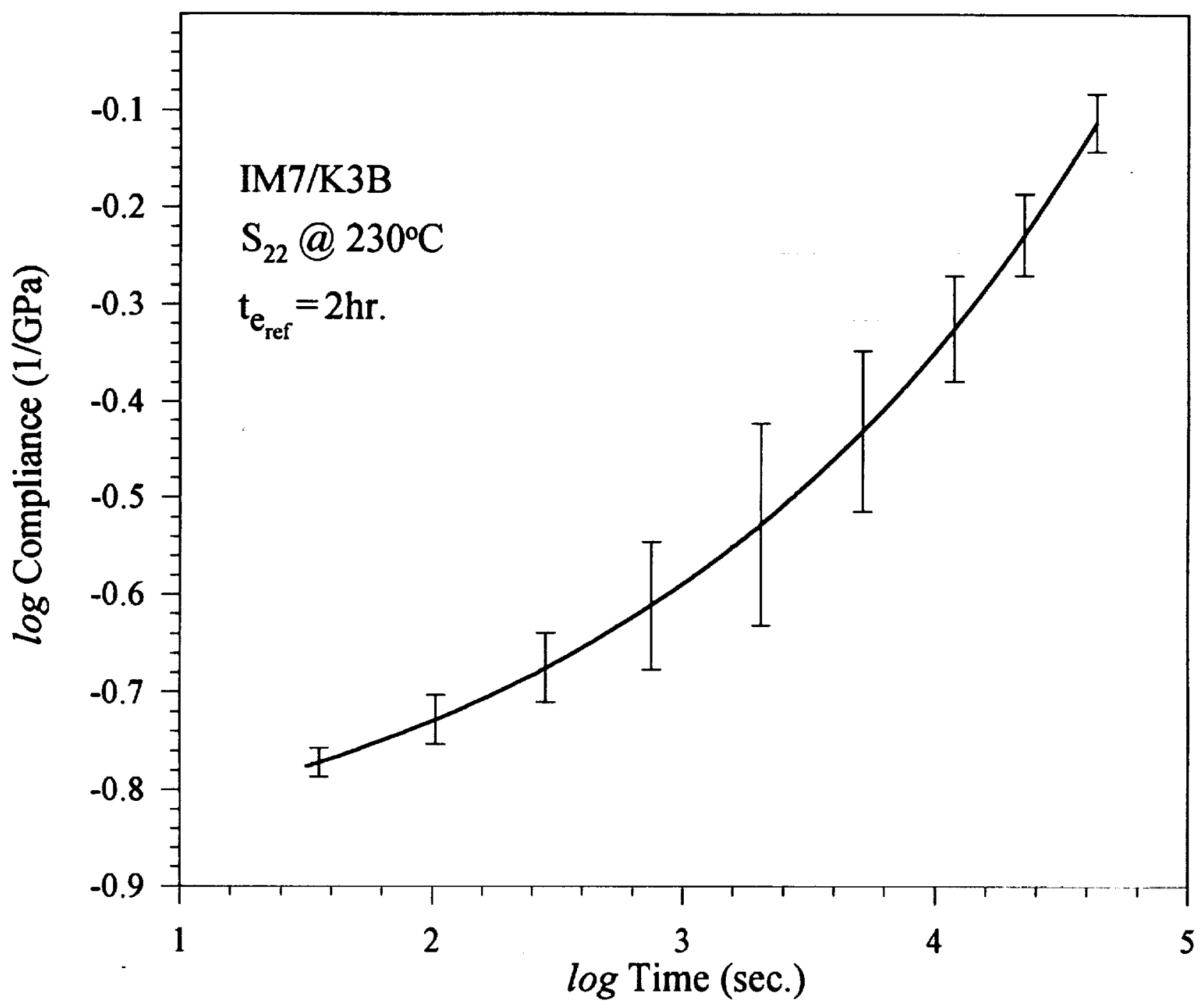

Figure 11: Transverse compliance $\mathrm{MMC}$ at $230^{\circ} \mathrm{C}$. 


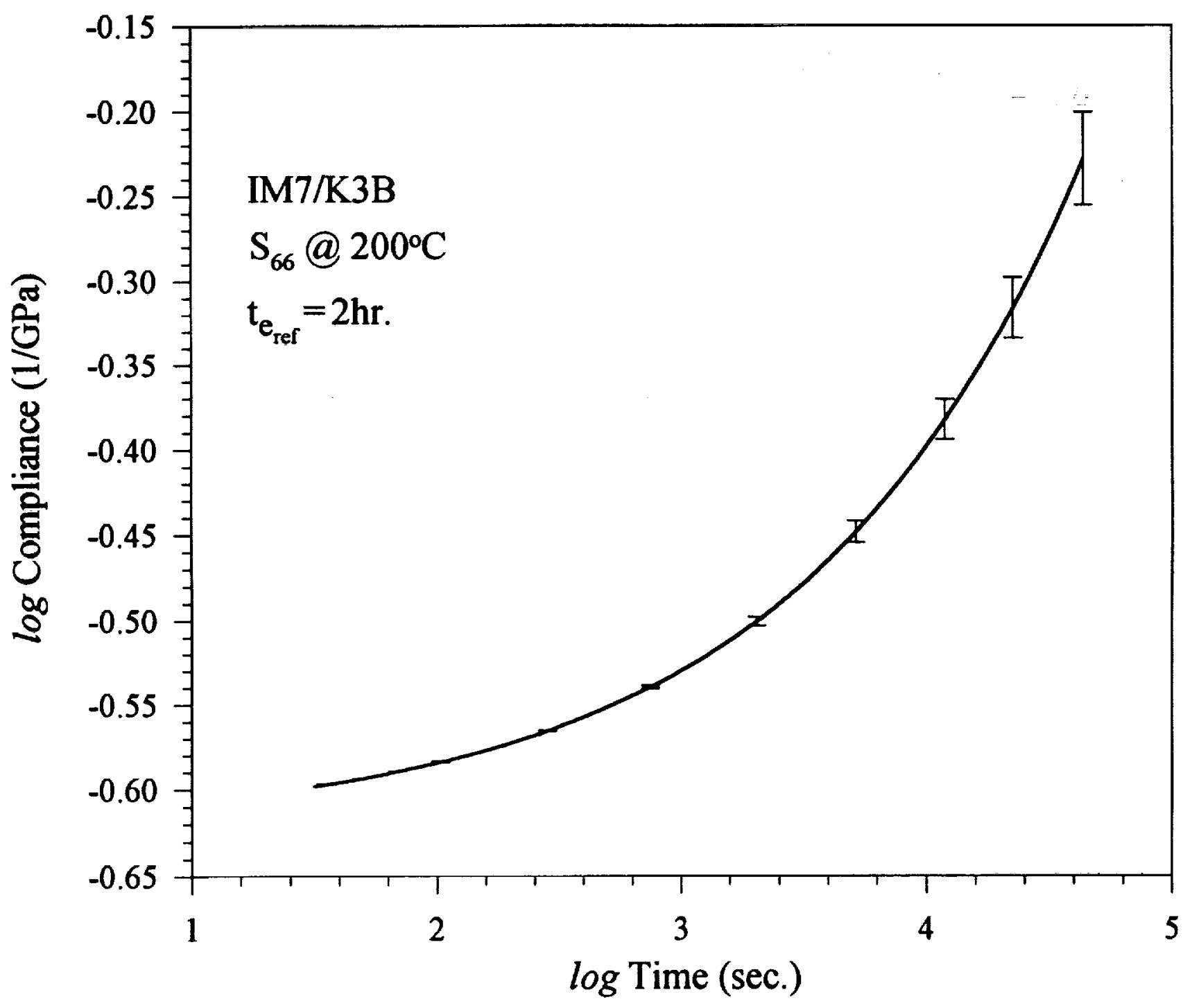

Figure 12: Shear compliance $\mathrm{MMC}$ at $200^{\circ} \mathrm{C}$. 


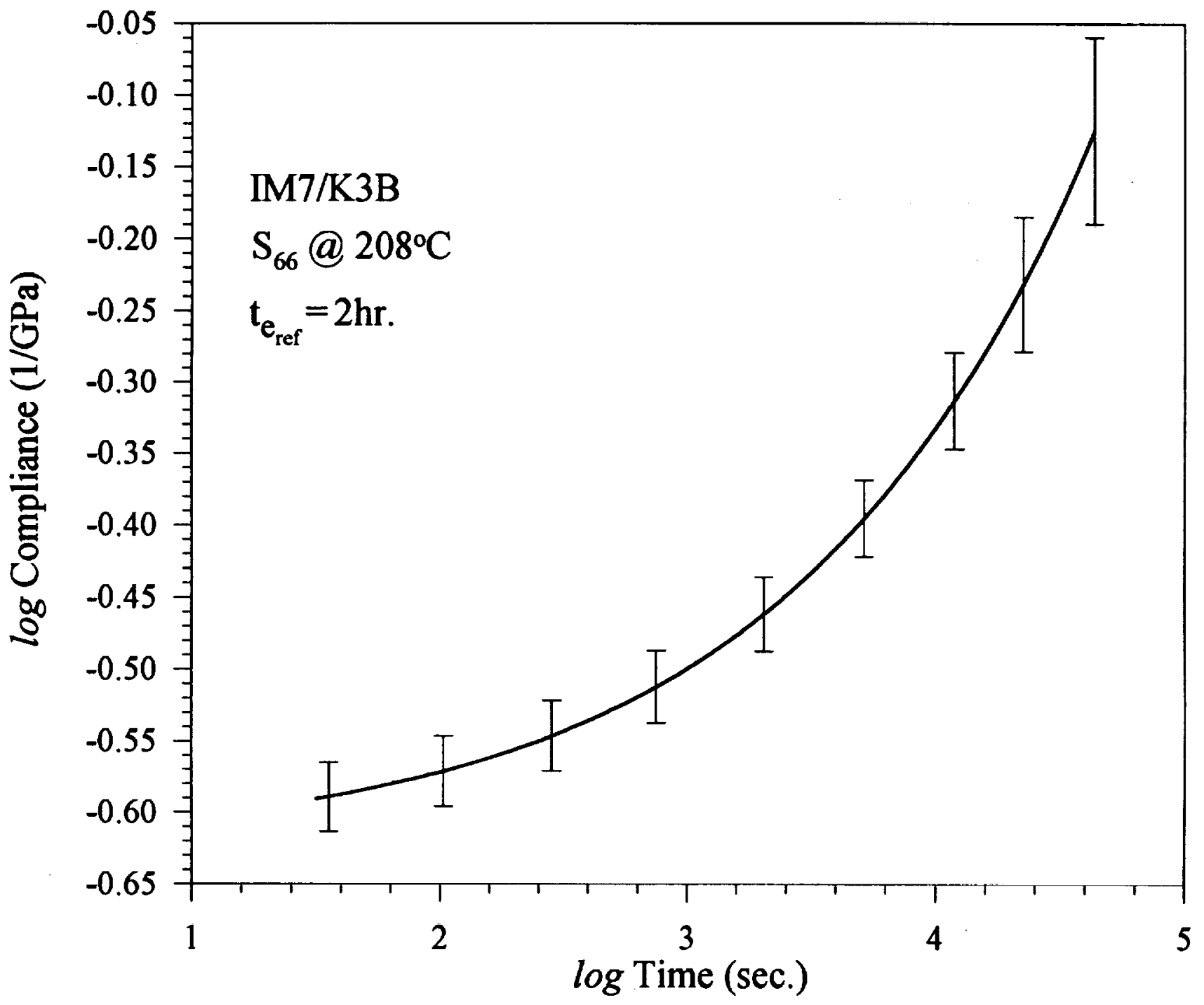

Figure 13: Shear compliance MMC at $208^{\circ} \mathrm{C}$. 


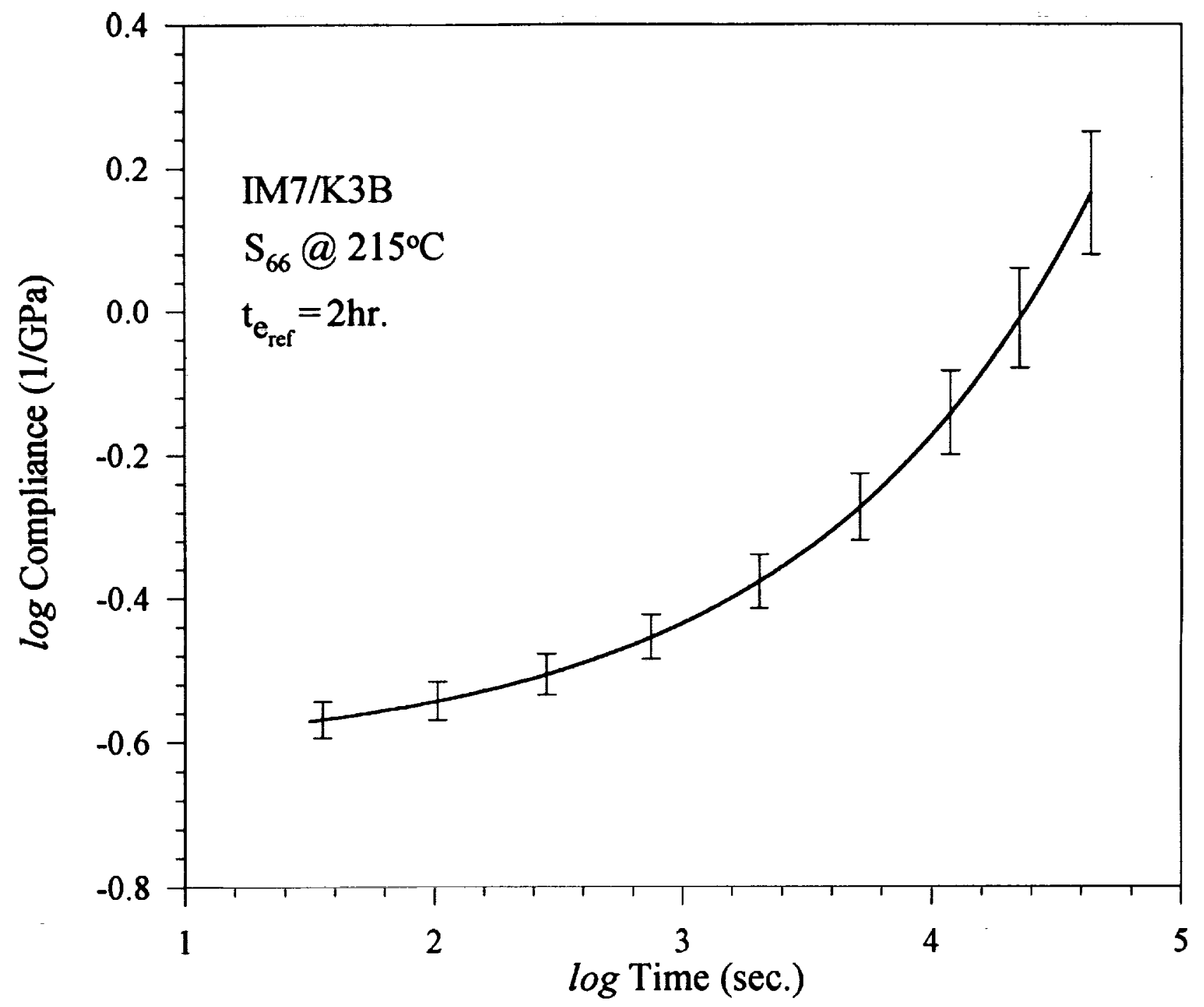

Figure 14: Shear compliance MMC at $215^{\circ} \mathrm{C}$. 


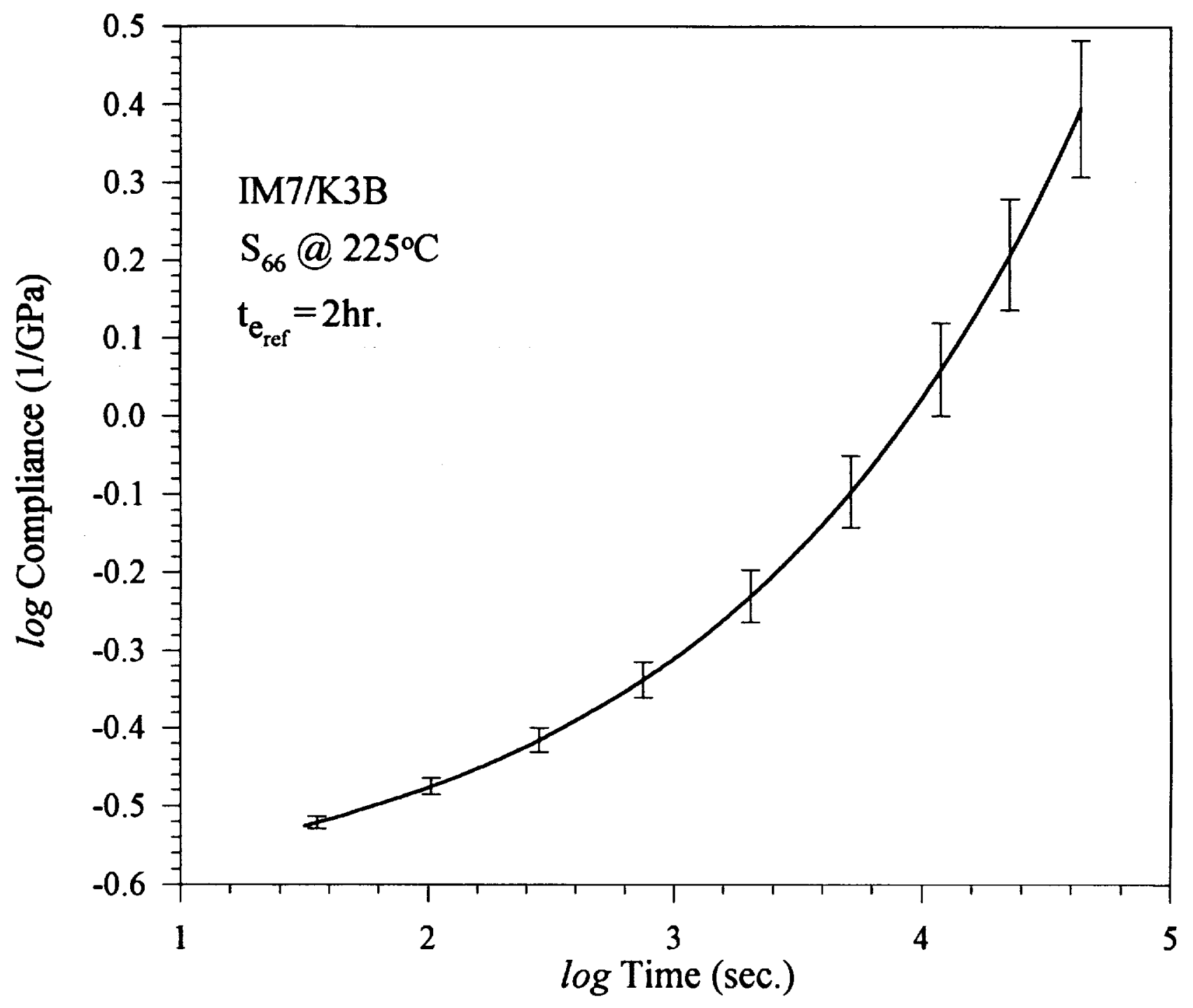

Figure 15: Shear compliance $M M C$ at $225^{\circ} \mathrm{C}$. 


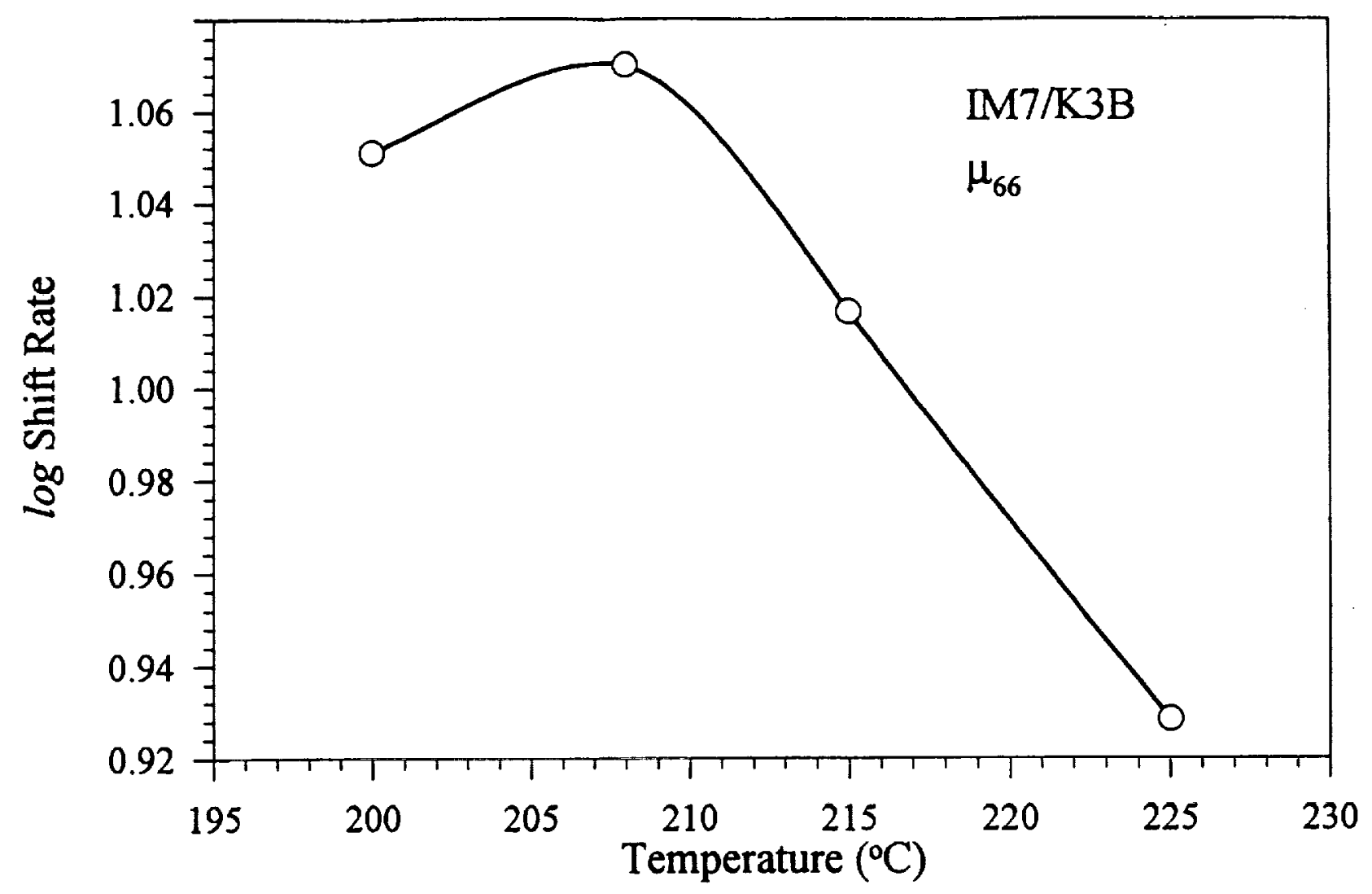

Figure 16: Shear compliance shift rate as a function of temperature.

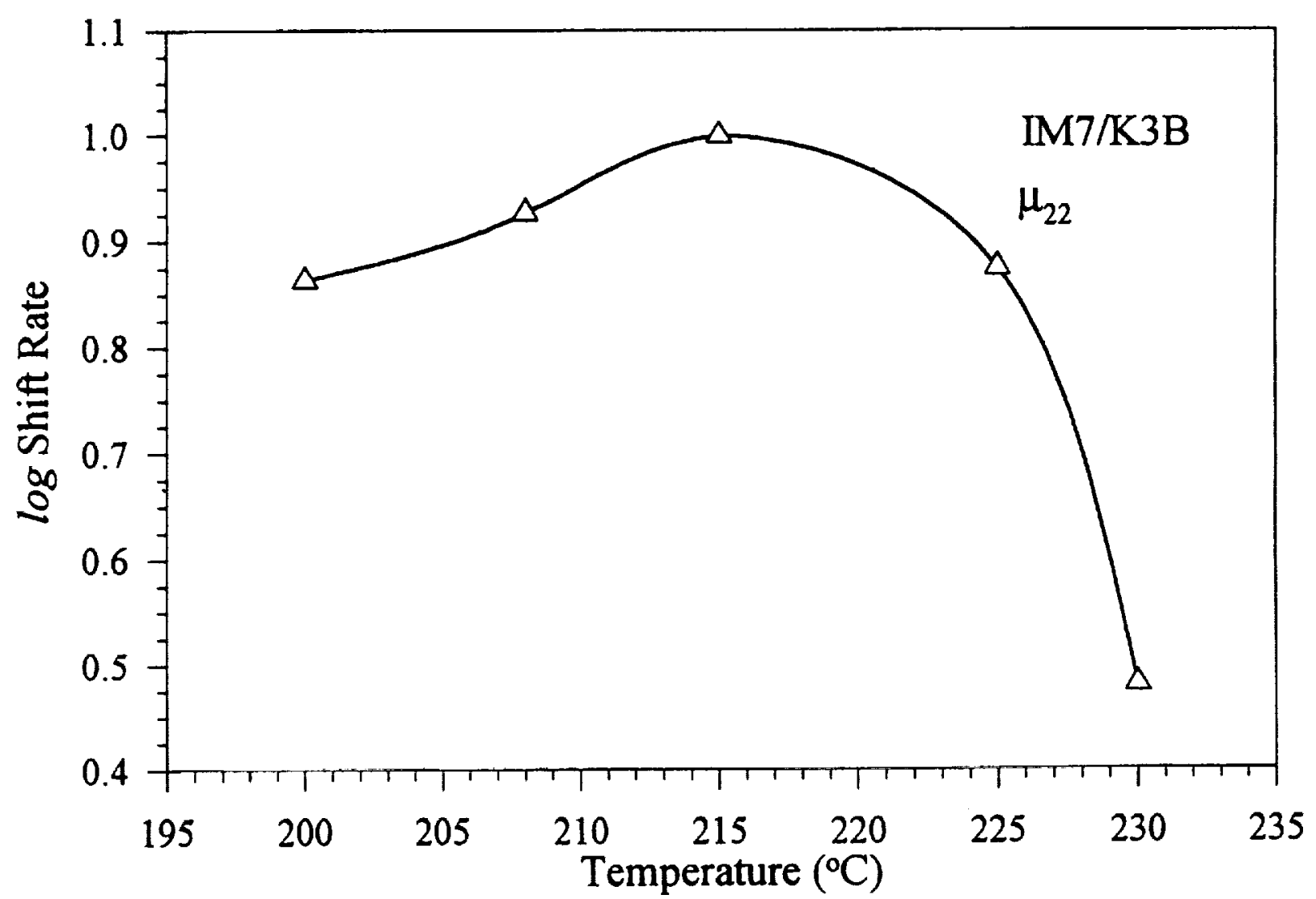

Figure 17: Transverse compliance shift rate as a function of temperature. 


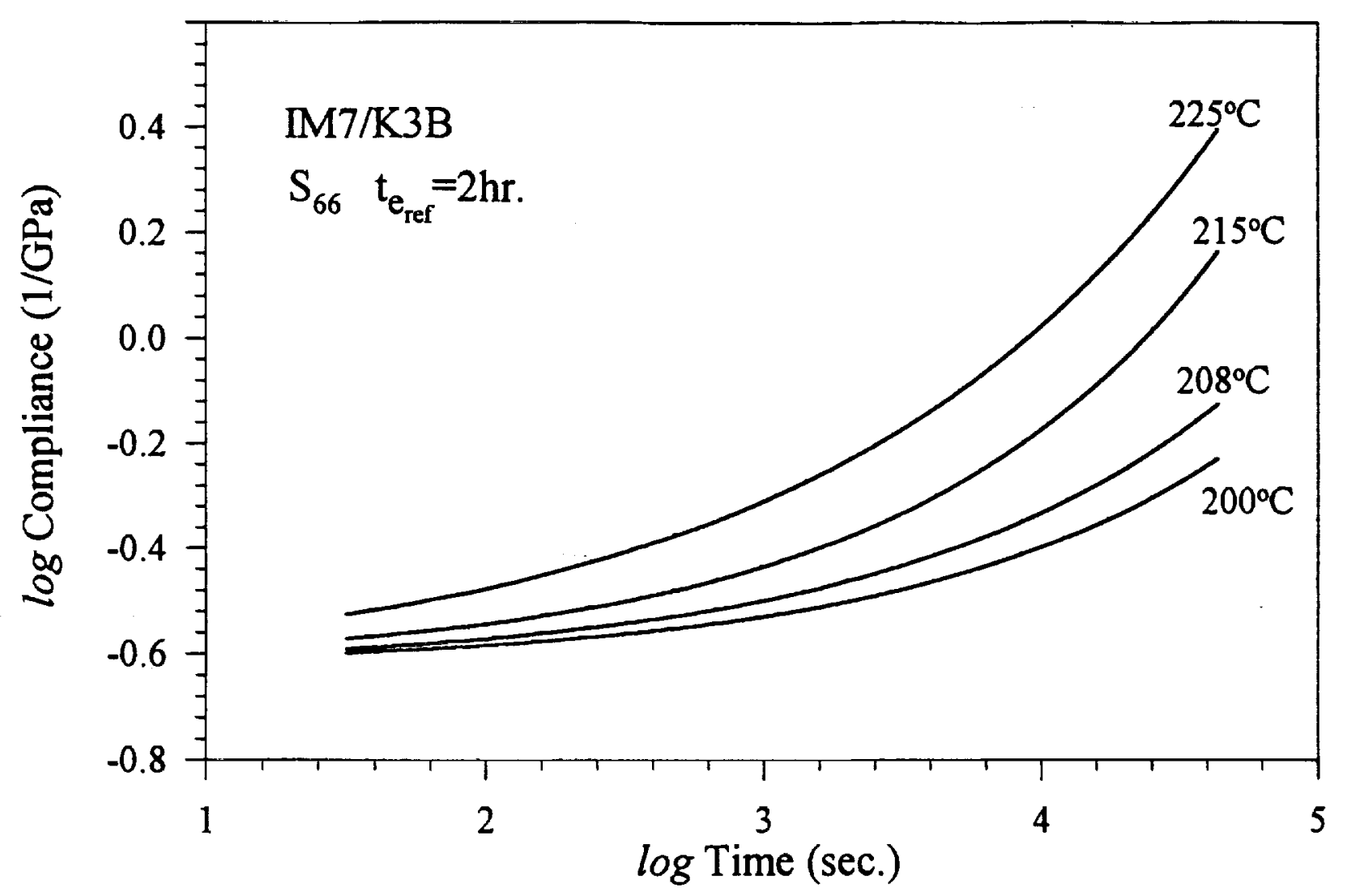

Figure 18: Shear compliance momentary master curves.

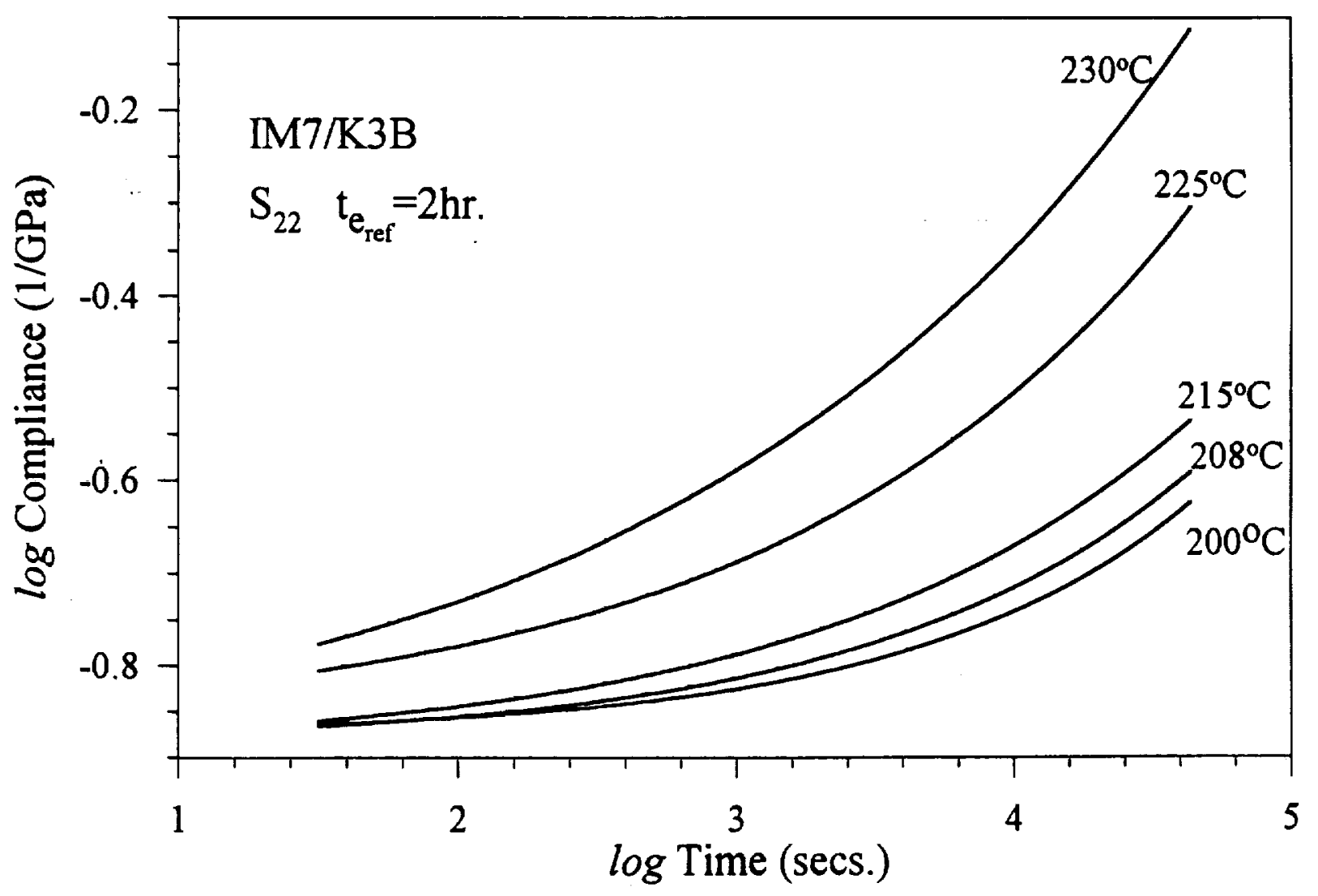

Figure 19: Transverse compliance momentary master curves 


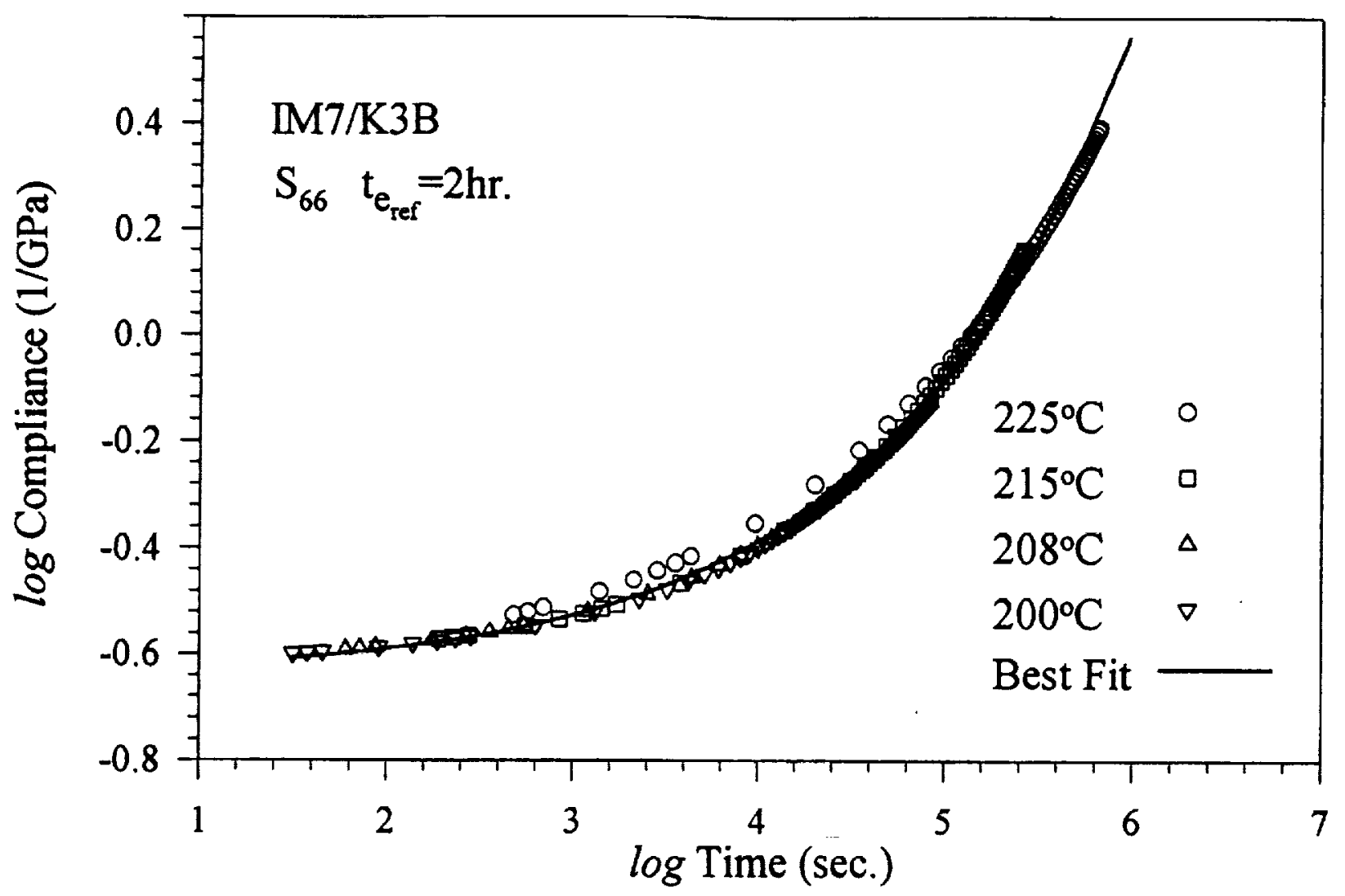

Figure 20: Shear compliance TTSP master curve $200^{\circ} \mathrm{C}$ to $225^{\circ} \mathrm{C}$.

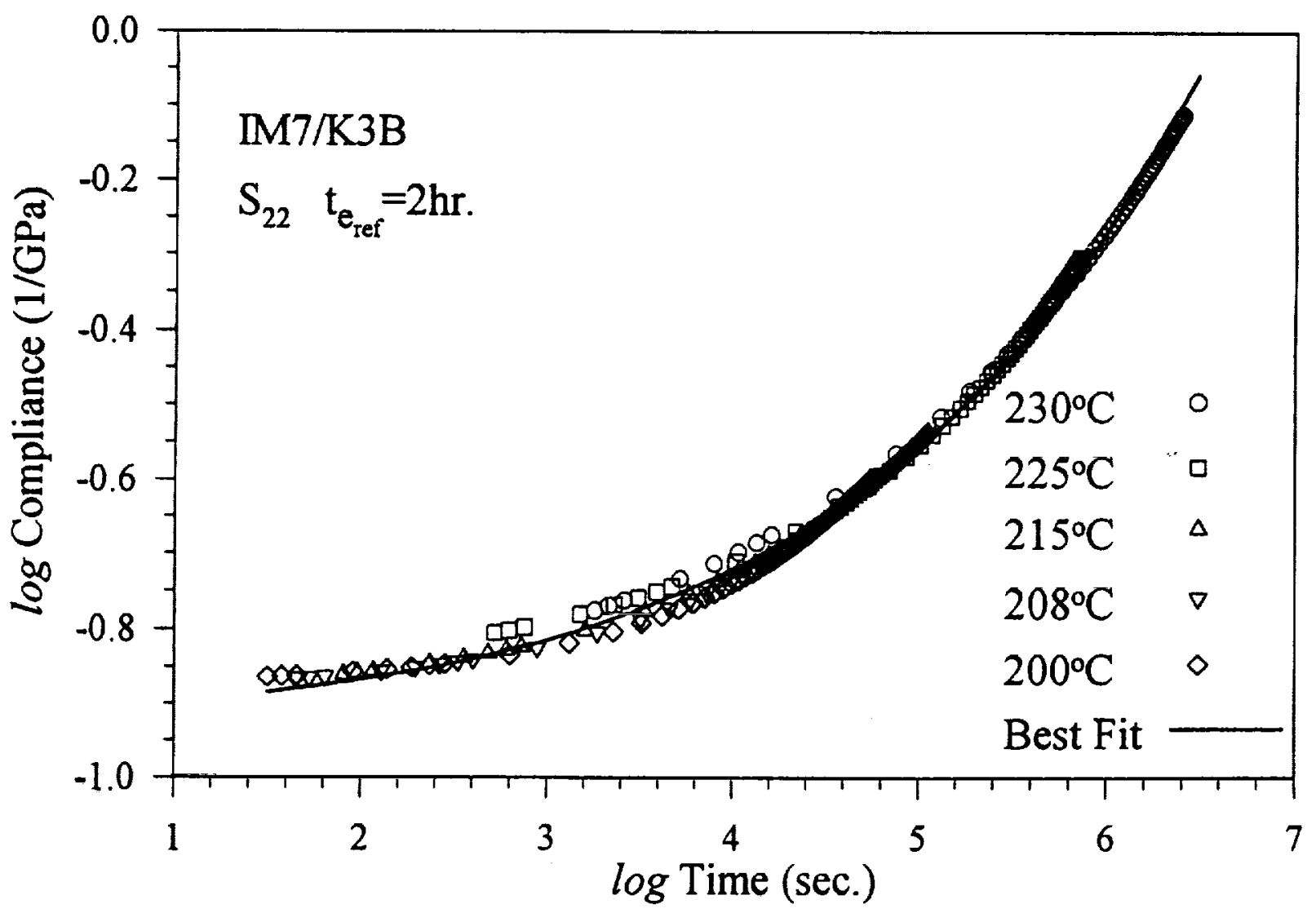

Figure 21: Transverse compliance TTSP master curve $230^{\circ} \mathrm{C}$ to $200^{\circ} \mathrm{C}$. 


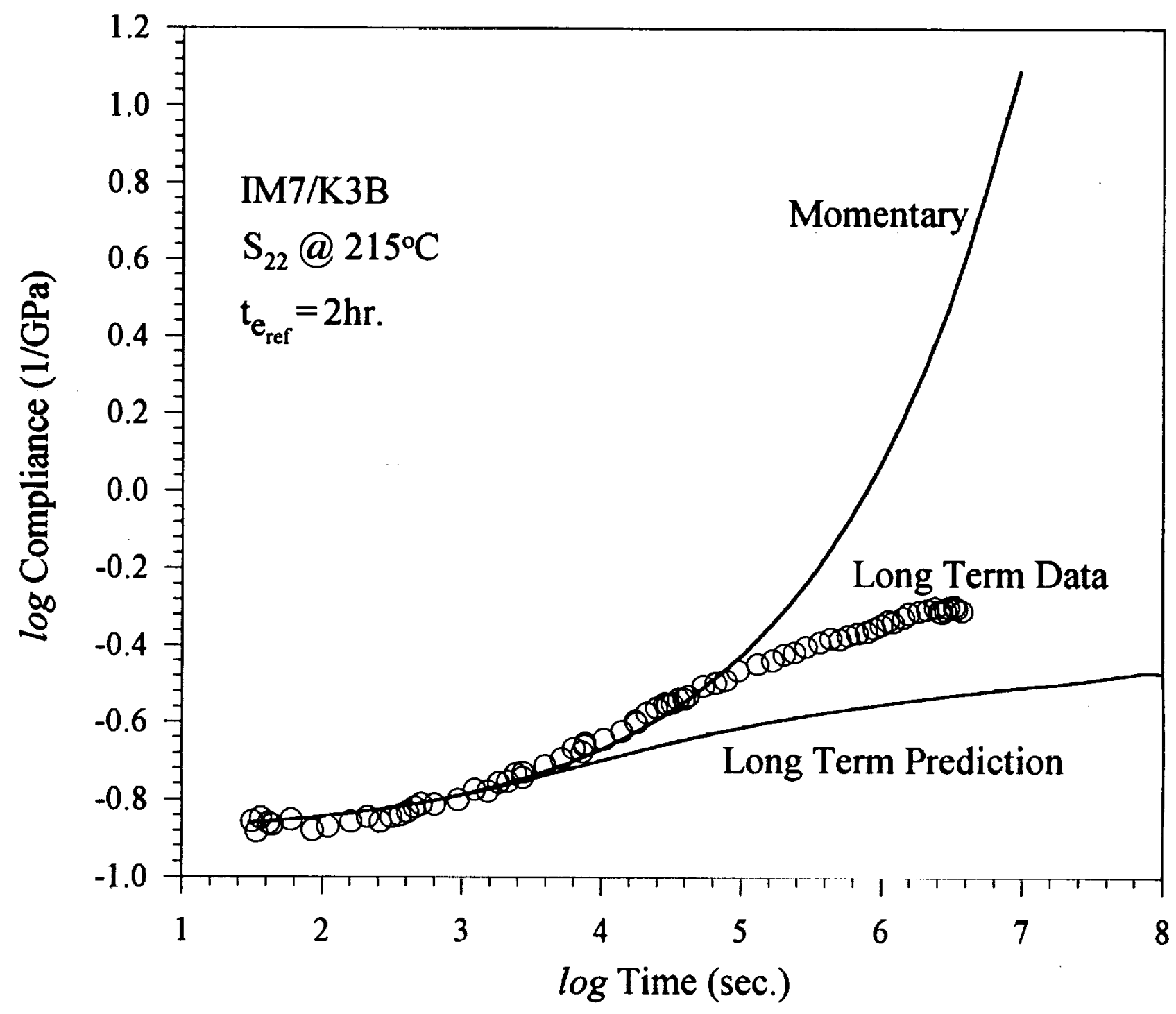

Figure 22: Long term test data versus prediction. 


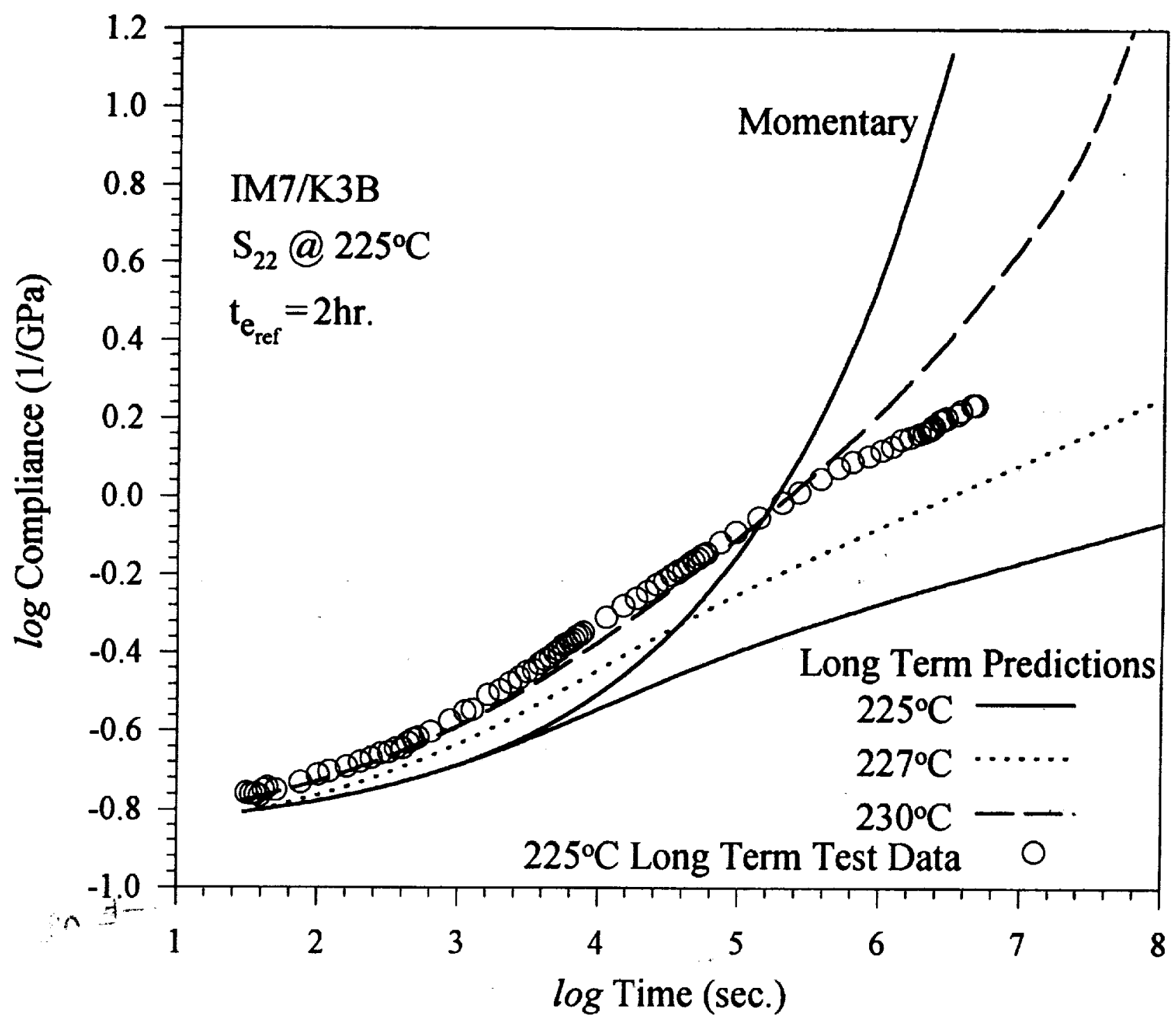

Figure 23: Long term test data versus prediction. 


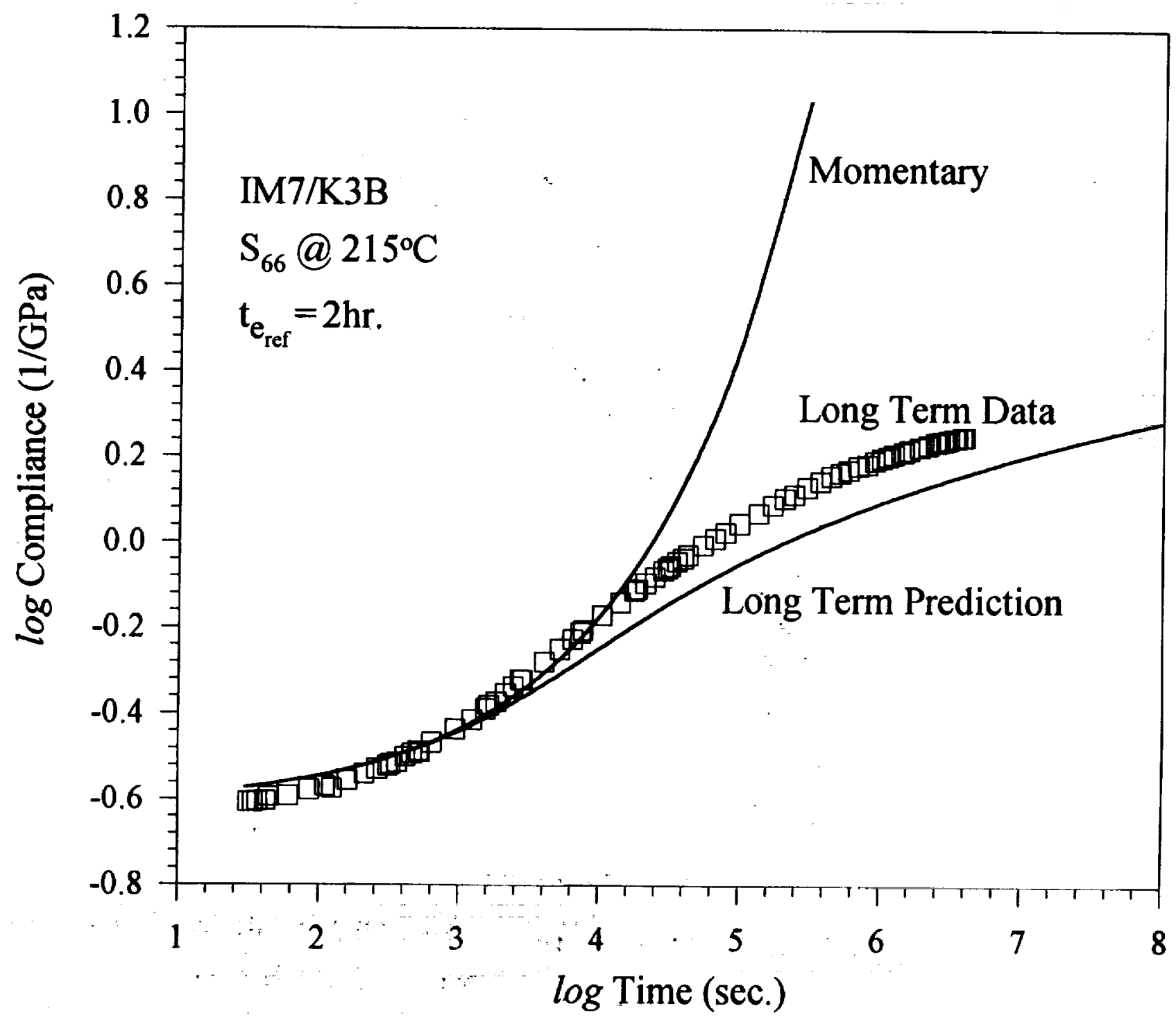

Figure 24: Long term test data versus prediction. 


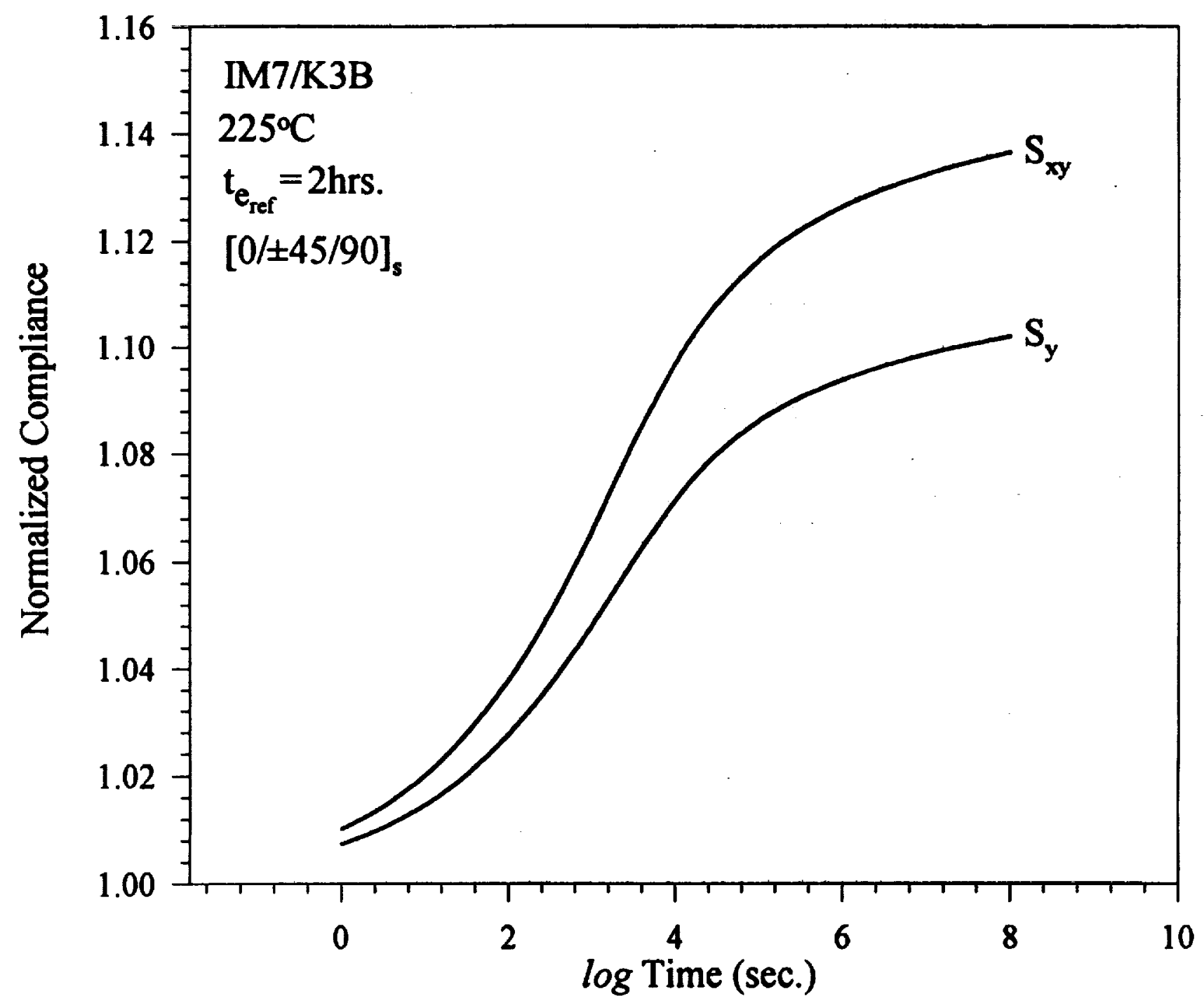

Figure 25: Prediction of the effects of aging on long term compliance. Directional dependency in a laminate is illustrated. 


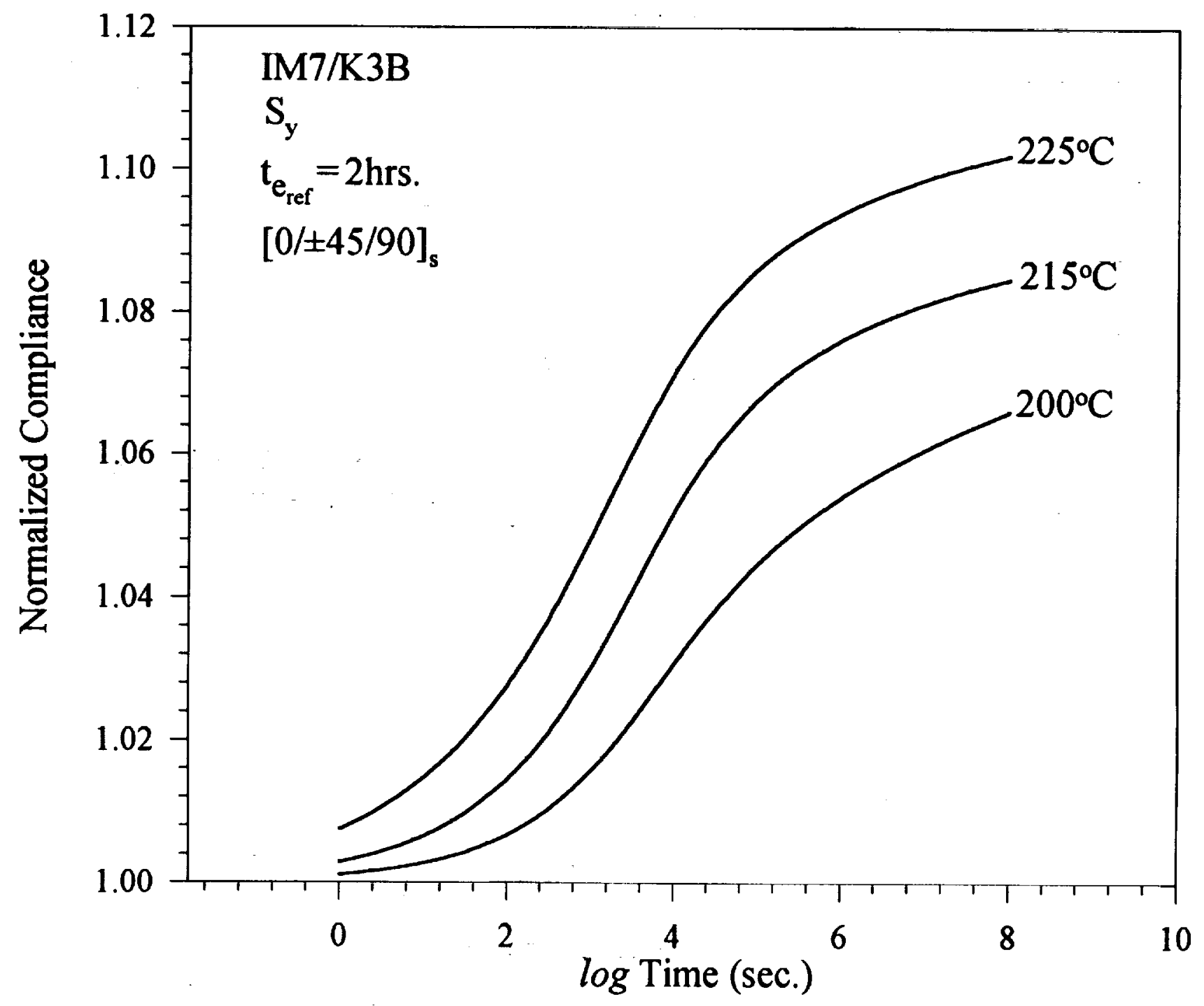

Figure 26: Prediction of the effects of aging on long term compliance. Temperature dependency in a laminate is illustrated. 


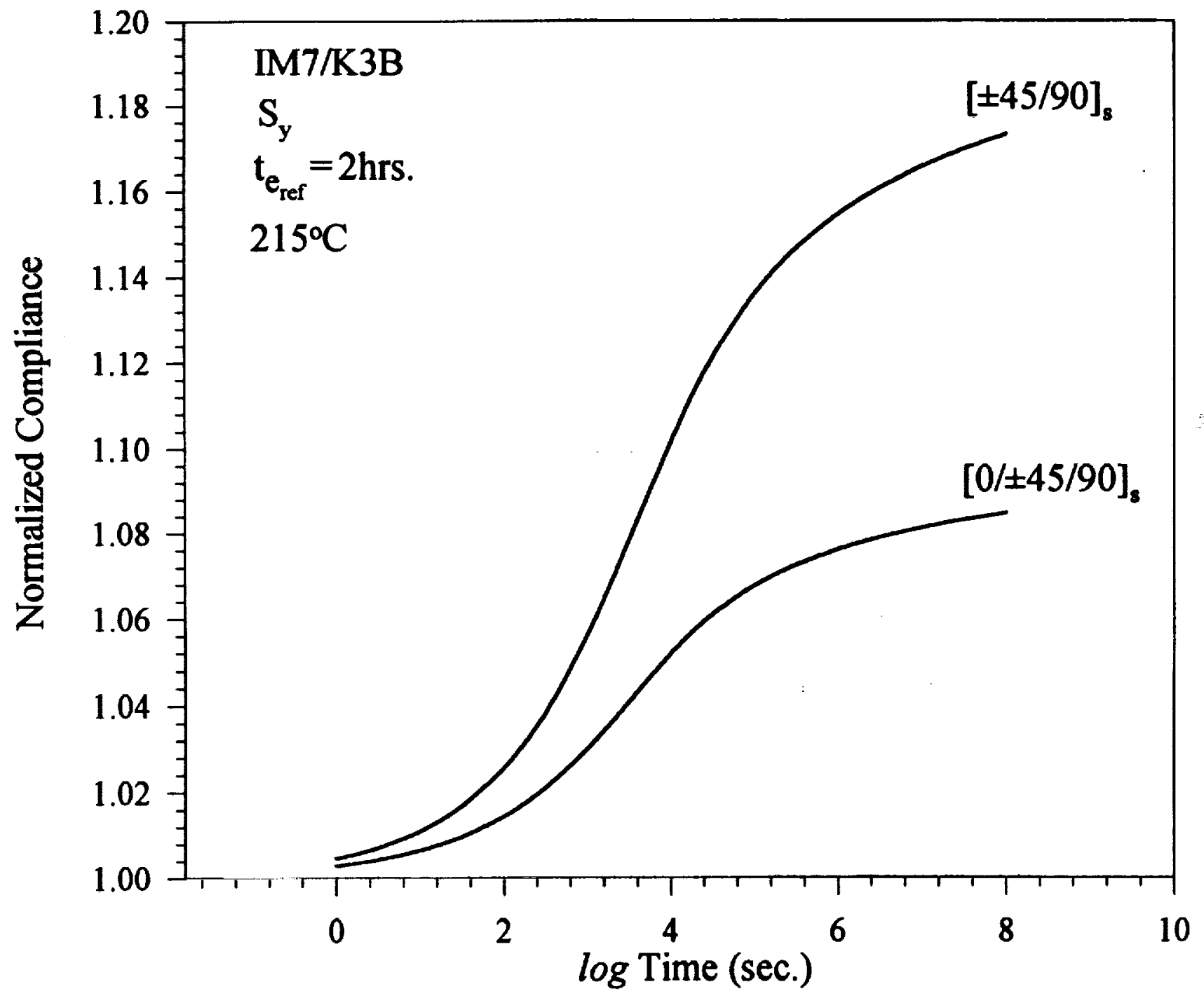

Figure 27: Prediction of the effects of aging on long term compliance. Laminate layup dependency is illustrated. 


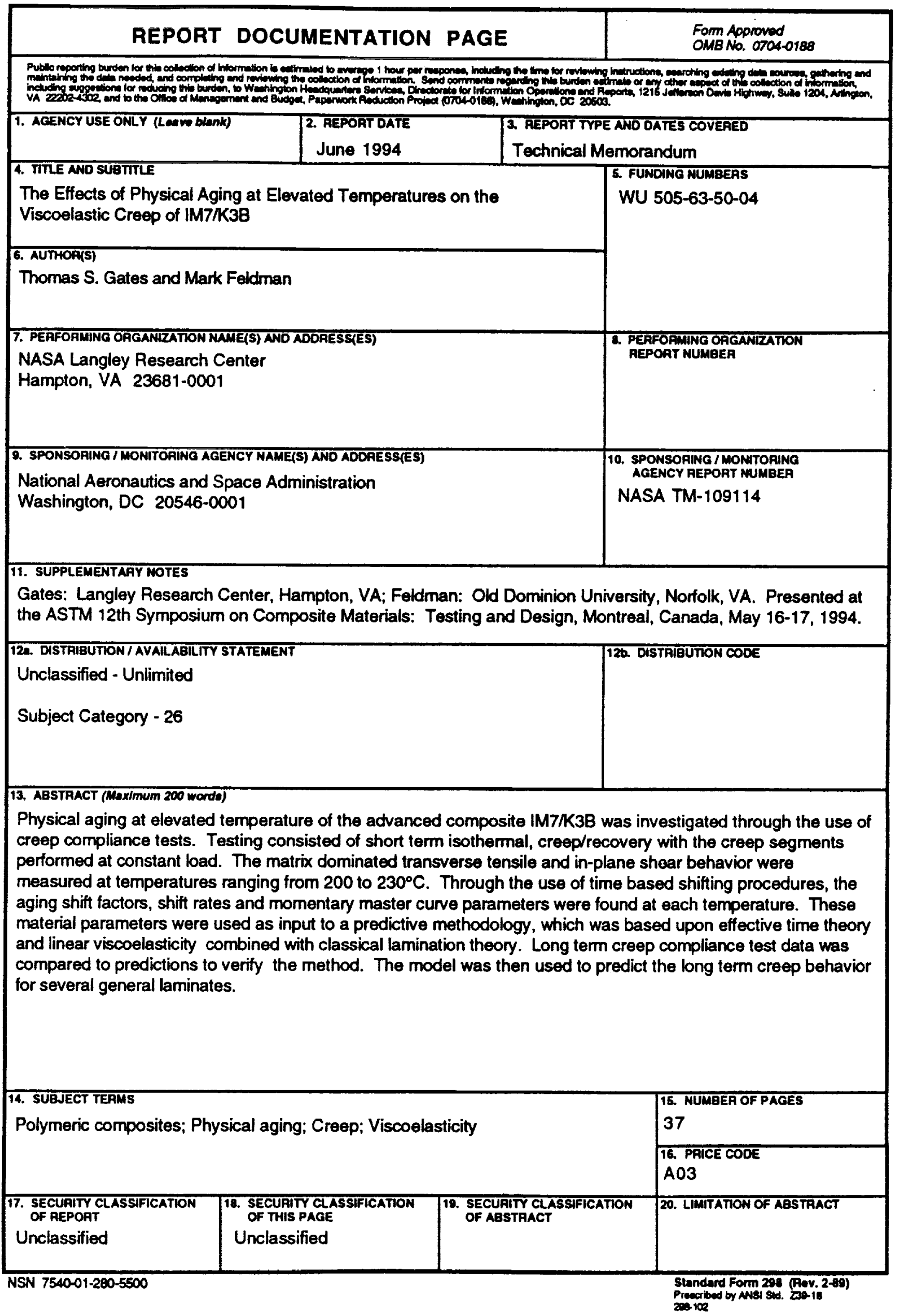

